\title{
FORÇA DE TRAÇÃO E DESEMPENHO OPERACIONAL DE HASTES SUBSOLADORAS EM SOLOS COM DIFERENTES TEXTURAS E UMIDADE
}

\section{CASSIANO MASSAKAZU SASAKI}

Engenheiro Florestal

Orientador: Prof. Dr. JOSÉ LEONARDO DE MORAES GONÇALVES

Dissertação apresentada à Escola
Superior de Agricultura "Luiz de
Queiroz", Universidade de São
Paulo, para a obtenção do título
de Mestre em Ciências, Área de
Concentração: Ciências Florestais.

PIRACICABA

Estado de São Paulo - Brasil

Outubro - 2000 
Dados Internacionais de Catalogaçāo na Publicaçāo (CIP)

DIVISĀO DE BIBLIOTECA E DOCUMENTAÇĀO - Campus "Luiz de Queiroz"/USP

\author{
Sasaki, Cassiano Massakazu \\ Força de tração e desempenho operacional de hastes subsoladoras em solos com \\ diferentes texturas e umidade / Cassiano Massakazu Sasaki. - - Piracicaba, 2000. \\ 53 p. : il. \\ Dissertação (mestrado) - - Escola Superior de Agricultura Luiz de Queiroz, 2000. \\ Bibliografia.
}

1. Avaliação de desempenho 2. Equipamento florestal 3. Preparo do solo 4. Subsolador 5. Tração I. Título

CDD 634.98

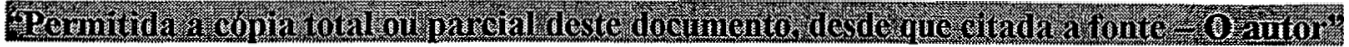


Aos meus pais, Newton e Lais, e minha querida Paula, pelo apoio, confiança e compreensão... 


\section{AGRADECIMENTOS}

Ao meu orientador, Prof. Dr. José Leonardo de Moraes Gonçalves, pela paciência, compreensão, orientação e, acima de tudo, amizade;

Ao amigo e colega, Sérgio Ricardo P. Bentivenha, pela alegria, apoio e solidariedade nos momentos mais difíceis da realização deste trabalho;

Aos Professores Antônio Natal Gonçalves, Fernando Seixas e Marcos Milan, pelas sugestões e propostas;

A Arador Máquinas e Equipamentos Agrícolas LTDA, pelo apoio e suporte técnico para a realização deste trabalho, em especial ao Francisco orlanda;

A Duratex S/A, pelo suporte técnico nas etapas de campo deste trabalho;

Aos operadores de máquinas, técnicos e engenheiros florestais da Duratex, pelo breve convivio e essencial colaboração;

Aos meus amigos e colegas, Paulo, Andre, Luciano, Lauro, Fábio e Paulo Henrique, pela amizade, alegria e convívio. 


\section{SUMÁRIO}

Página

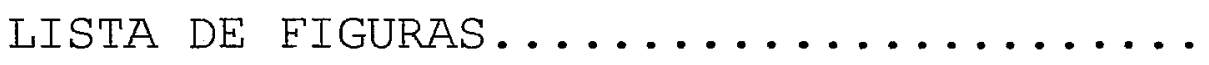

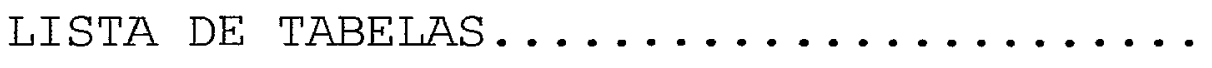

RESUMO $\ldots \ldots \ldots \ldots \ldots \ldots \ldots \ldots \ldots$

SUMMARY $\ldots \ldots \ldots \ldots \ldots \ldots \ldots \ldots$

1 INTRODUÇÃO $\ldots \ldots \ldots \ldots \ldots \ldots \ldots \ldots$

2 REVISÃO DE LITERATURA.............

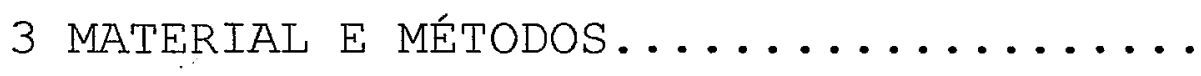

4 RESULTADOS E DISCUSSÃO...........

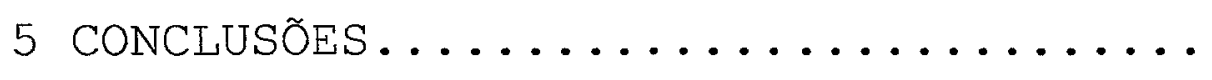




\section{LISTA DE FIGURAS}

Página

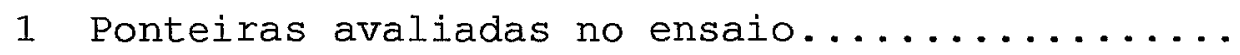

2 Hastes avaliadas no ensaio................

3 Método indireto de determinação da força de tração em máquinas acopladas ao engate de três

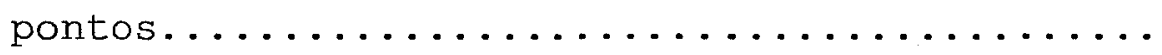

4 Resistência dinâmica inicial do RQ e do LVA, úmidos e secos, na linha e entrelinha do

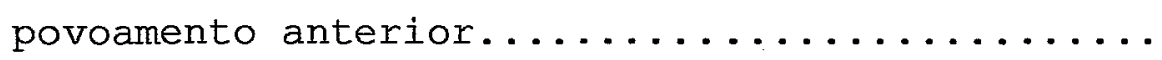

5 Esquema do perfil de solo mobilizado após a subsolagem: a) Vista de cima da faixa de solo preparado e b) Vista vertical da seção de solo

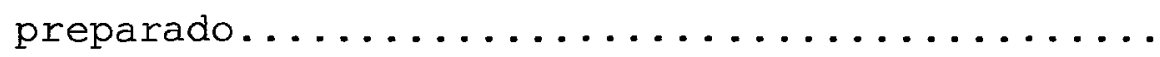

6 Correlação entre algumas variáveis estudadas...

7 Força de tração, patinagem e resistência específica operacional de acordo com o tipo de haste, solo e umidade................. 


\section{IISTA DE TABELAS}

Página

1 Chave de classificação para máquinas de

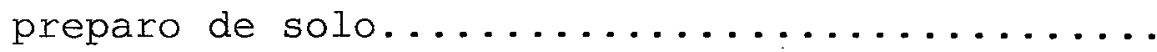

2. Resultados da análise granulométrica

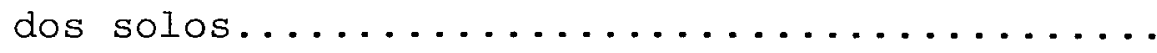

3 Resultados da análise química dos solos.......

4 Descrição dos tratamentos experimentais.......

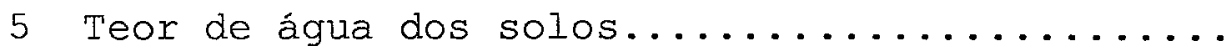

6 Valores médios da análise conjunta dos dados para força de tração (FT), potência na barra de tração (PBT), velocidade de deslocamento (VD), patinagem (PAT), resistência específica operacional(REO), capacidade efetiva de trabalho (CET), profundidade efetiva de trabalho (PET) e área de solo mobilizada (ASM), obtidos para as diferentes variáveis

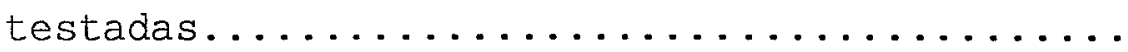

7 Valores médios da força de tração considerando - efeito interativo de duas variáveis isoladamente, obtidos através da decomposição dos graus de liberdade da interação entre as diferentes variáveis testadas.................... 
8 Valores médios da profundidade efetiva de trabalho considerando o efeito interativo de duas variáveis isoladamente, obtidos através da decomposição dos graus de liberdade da interação entre as diferentes variáveis testadas.......

9 Valores médios da patinagem considerando o efeito interativo de duas variáveis isoladamente, obtidos através da decomposição dos graus de liberdade da interação entre as diferentes variáveis testadas....................

10 Valores médios da resistência específica operacional considerando o efeito interativo de duas variáveis isoladamente, obtidos através da decomposição dos graus de liberdade da interação entre as diferentes variáveis testadas....... 


\section{FORÇA DE TRAÇÃO E DESEMPENHO OPERACIONAI DE HASTES SUBSOLADORAS EM SOLOS COM DIFERENTES TEXTURAS E UMIDADE}

Autor: CASSIANO MASSAKAZU SASAKI

Orientador: Prof. Dr. JOSÉ LEONARDO DE MORAES GONÇALVES

\section{RESUMO}

Três configurações de hastes subsoladoras, duas parabólicas e uma reta-inclinada, utilizando-se ponteiras com e sem asa, foram avaliadas em áreas florestais manejadas sob cultivo mínimo do solo, num Neossolo Quartzarênico (RQ) e num Latossolo Vermelho-Amarelo A moderado, álico, textura média. (LVA), localizados em Itatinga (SP) e Paranapanema (SP), respectivamente. As avaliações foram realizadas em dois períodos distintos, inverno e verão, e duas profundidades de trabalho, 20 e $40 \mathrm{~cm}$, com os objetivos de avaliar a demanda de força de tração e o desempenho operacional de três hastes subsoladoras em solos com diferentes composições texturais, em duas profundidades de trabalho e dois níveis de umidade do solo. Os três tipos de hastes avaliados não diferiram entre si quanto a demanda por força de tração e desempenho operacional. Houve diferença para a profundidade efetiva de trabalho e a área de solo mobilizado, parâmetros em que a haste reta-inclinada apresentou os melhores resultados. As ponteiras com asa apresentaram cerca de $20 \%$ a mais de força de tração, $22 \%$ menos resistência específica operacional e mobilizaram 20\% mais solo do que as ponteiras sem asa. Com o aumento da profundidade de trabalho, de 20 para $40 \mathrm{~cm}$, houve incremento da força de tração, da potência na barra de tração e da patinagem. Não houve diferença entre os solos quanto à força 
de tração exigida, apesar do LVA apresentar $37 \%$ a mais de patinagem e $42 \%$ a mais de resistência especifica operacional, quando comparado com o RQ. O LVA também apresentou menor profundidade efetiva de trabalho e menor área de solo mobilizado. Independentemente do tipo de haste, presença ou não de asas na ponteira, profundidade de trabalho e tipo de solo, a demanda de força de tração foi menor para o solo seco. O solo seco também proporcionou menor patinagem, menor resistência específica operacional e maior capacidade efetiva de trabalho, quando comparado com o solo úmido. 


\title{
TRACTION FORCE AND OPERATIONAI PERFORMANCE OF SUBSOILING TINES IN SOILS WITH DIFEERENT TEXTURES AND MOISTURE
}

\author{
Author: CASSIANO MASSAKAZU SASAKI \\ Adviser: Prof. Dr. JOSÉ LEONARDO DE MORAES GONÇALVES
}

\section{SUMMARY}

Three configurations of subsoiling tines, two parabolic and one inclined, using chisels with and without wings, were evaluated in forest areas managed under minimum cultivation of the soil, in a "Neossolo Quartzarênico" (RQ) and in a "Latossolo Vermelho-Amarelo" (LVA), medium texture, located in Itatinga (SP) and Paranapanema (SP), respectively. The evaluations were accomplished in two different periods, winter and summer, and in two work depths, 20 and $40 \mathrm{~cm}$, with the objectives of evaluating the demand of traction force and the operational performance of three subsoiling tines in soils with different texture, in two work depths and two levels of soil moisture. The three tine types didn't differ from each other as far as the demand for traction force and operational performance are concerned. There was difference between the effective depth of work and the area of mobilized soil, parameters in which the inclined tine presented the best results. The chisels with wings presented 20\% more traction force, $22 \%$ less specific operational resistance and mobilized 20 응 more soil than the chisels without wings. With the deepening of the work depth, from 20 to $40 \mathrm{~cm}$, there was increase in traction force, potency in the traction bar and skating. There was no difference between the soils when the traction force was evaluated, in spite of LVA presenting $37 \%$ 
more skating and $42 \%$ more operational specific resistance, when compared to RQ. LVA also presented smaller effective depth of work and smaller area of mobilized soil. Independently of the tine type, whether were wings in the chisel or not, work depth and soil type, the demand of traction force was smaller for the dry soil. The dry soil also provided less skating, less specific operational resistance and more effective capacity of work, when compared to the humid soil. 


\title{
1 INTRODUÇÃO
}

O tráfego de máquinas e implementos sobre solos usados para fins florestais implica, freqüentemente, em sua compactação superficial. Isto se deve às características inerentes de cada solo e, também, ao uso incorreto de máquinas e implementos. Com o surgimento das camadas de compactação, faz-se necessário procurar modos de rompê-las, através do projeto e desenvolvimento de equipamentos apropriados à área florestal, uma vez que os disponíveis foram desenvolvidos para condições de trabalho em áreas agrícolas.

\begin{abstract}
Dentre os diversos equipamentos utilizados atualmente para o rompimento de camadas compactadas, estão os subsoladores. Estes equipamentos são constituídos basicamente por uma haste curva, inclinada ou reta, que tem por função penetrar no solo e propagar forças que rompam sua estrutura, o que melhora a aeração e drenagem interna do solo, diminuí o escoamento superficial e o tempo de encharcamento do solo e acelera consideravelmente o crescimento inicial das mudas, reduzindo a demanda de práticas de controle de plantas invasoras.
\end{abstract}

$\mathrm{Na}$ área florestal, o subsolador vem sendo utilizado cada vez com maior intensidade, principalmente em áreas onde o cultivo mínimo do solo é aplicado. Apesar disto, 
ainda existe grande empirismo no uso do subsolador, seja quanto à profundidade ou umidade ideal de preparo do solo, tipo e número de hastes e utilização ou não de asas na ponteira do implemento.

Os objetivos deste trabalho foram avaliar a demanda de força de tração e o desempenho operacional de três hastes subsoladoras em solos com diferentes composições texturais, em duas profundidades de trabalho e dois níveis de umidade do solo. 


\section{REVISÃO DE LITERATURA}

o preparo de solo pode ser definido como a manipulação física, química ou biológica do mesmo, com o objetivo de eliminar as plantas não desejáveis, obter condições favoráveis para a colocação de sementes ou partes vivas de plantas no solo, manutenção da fertilidade e da produtividade do solo ao longo do tempo, eliminação de camadas compactadas, incorporação de calcário, fertilizantes e restos vegetais e nivelamento do terreno. (Castro, 1994).

O surgimento de camadas compactadas no solo pode ocorrer desde o manejo até a colheita da madeira, ocasionado por cargas aplicadas sobre a superfície do solo pelos rodados de máquinas que participam nas diversas operações mecanizadas (Seixas, 1996). Essa compactação pode ser definida como a densificação do solo através da aplicação de uma carga dinâmica, causando assim um decréscimo na porcentagem de poros do solo, devido à mudanças na posição relativa dos grãos e agregados do solo (Li, citado por Seixas, 1999).

Esse tipo de compactação, caracterizado pelo tráfego de máquinas, ocorre geralmente no terço inicial do perfil do solo (Rípoli et al., 1985). A intensidade de compactação do solo depende da pressão exercida pelos pontos de apoio dos veículos, suas cargas e equipamentos, camada de 
resíduos vegetais, número de vezes que os caminhos são atravessados e da textura, umidade e agregação do solo (Seixas, 1988 e Seixas, 1999).

Dentre as mudanças que a compactação promove nas propriedades físicas do solo estão o aumento na densidade natural do mesmo, decréscimo no volume de macroporos, infiltração e movimento interno de água mais lentos, aeração mais pobre e maior resistência mecânica do solo ao crescimento de raízes (Seixas, 1988). A compactação influí, ainda, na susceptibilidade à erosão dos solos. A erosão superficial arrasta particulas de solos das áreas de maior para menor cota. Sua ocorrência ou não depende, basicamente, do índice de infiltração de água no perfil do solo e, da capacidade de armazenamento desse, que é função de sua porosidade (Rípoli et al., 1985).

Segundo Rípoli et al. (1985), a compactação afeta o crescimento das plantas, do ponto de vista fisiológico, devido a:

- redução do volume de macroporos, dificultando a taxa de infiltração de água e diminuindo as trocas gasosas na massa do solo (diminuindo o oxigênio disponível às raízes);

- certos elementos, como o manganês (Mn) e o ferro (Fe), podem passar à formas reduzidas em meios pobres em oxigênio, tornando-se tóxicos às raízes e sendo de difícil correção;

- os enrrugamentos e torções de raízes em camadas compactadas dificultam a absorção e translocação da solução nutritiva 
para a parte aérea das plantas, devido aos danos causados nos vasos vasculares das raízes;

- em determinadas culturas, como as leguminosas, a compactação leva a planta a desenvolver maior número de raízes, porém mais finas e curtas.

A fim de se prevenir a compactação devido à utilização de máquinas, sugere-se o "controle de tráfego", que significa restringir a movimentação de veículos em uma menor área, manter o tráfego dentro do talhão em trilhas prédefinidas, procurar evitar o salto dos equipamentos, desenvolver máquinas que realizem diversas operações ao mesmo tempo, aplicar o cultivo mínimo do solo, evitar carga excessiva, planejar as operações nas épocas que o solo é menos sensível à compactação, usar pneus com carcaça flexível, largos e com baixa pressão de inflação (Seixas, 1988; Seixas, 1996 e Seixas, 1999).

Segundo Srivastava et al. (1993), os principais objetivos do preparo do solo são:

- desenvolver estrutura do solo adequada ao plantio. A estrutura granular adequada é primordial para permitir rápida infiltração e boa retenção da água da chuva, promovendo a aeração adequada do solo e minimizando a resistência do solo à penetração das raízes;

- controlar plantas invasoras ou remover culturas indesejáveis; 
- manejar residuos vegetais, através da incorporação dos resíduos ou apenas da manutenção destes sobre o solo, contribuindo para o aumento da fertilidade e redução da erosão;

- estabelecer o planejamento futuro do plantio, irrigação, drenagem ou colheita;

- incorporar e misturar fertilizantes, pesticidas, adubos orgânicos, etc. ao solo;

- realizar segregações, que envolvem a retirada de pedras, objetos estranhos ao ambiente ou raízes dos solos a serem preparados.

Gadanha Júnior et al. (1991), afirmam que o preparo de solo é um conjunto de operações agrícolas de mobilização do mesmo, realizadas antes da implantação da cultura comercial, com o objetivo de tornar o solo capaz de receber órgãos de propagação das plantas. Essas operações também incluem a incorporação de residuos vegetais, fertilizantes e corretivos distribuídos a lanço.

Dentre as diversas operações que podem realizar o preparo de solo, está a subsolagem, prática que deve ser aplicada apenas sob determinadas condições. A subsolagem é necessária quando ocorreram situações de ordem física prejudiciais ao desenvolvimento normal do sistema radicular, além de dificultar os processos de armazenamento e de disponibilidade de água e aeração do solo (Gadanha Júnior et al., 1991; Rípoli et al., 1985). 
A subsolagem é definida por Nichols \& Reaves (1958) como uma operação de preparo de solo realizada normalmente entre 0,30 e $0,40 \mathrm{~m}$ de profundidade. A American Society of Agricultural Engineers, ASAE, caracterizou a subsolagem, em 1982, como sendo uma cinzelagem profunda, abaixo de $0,40 \mathrm{~m}$, com o propósito de desestruturar o solo, melhorando o crescimento das raizes em profundidade. O termo cinzelagem é definido pela ASAE (1982) como a operação na qual uma ferramenta estreita rompe camadas adensadas do solo, em profundidades de até $0,40 \mathrm{~m}$.

Para Taylor \& Beltrame (1980), a subsolagem, em termos físicos, é uma técnica utilizada basicamente para romper camadas de solo que tenham sofrido compactação ou, mesmo, perfis de solo mais densos. O rompimento das camadas compactadas traz benefícios imediatos, como a diminuição da resistência do solo à penetração das raízes, o aumento no volume dos macroporos, que melhora a aeração e drenagem interna do solo e permite um fluxo vertical mais rápido da água, diminuindo o escoamento superficial e o tempo de encharcamento do solo.

Rípoli et al. (1985) afirmam que a principal função da subsolagem é o rompimento das camadas de solo adensadas, possibilitando a infiltração da água, melhor penetração do sistema radicular para maior área de exploração do solo, melhor aeração e trocas gasosas, melhor drenagem e diminuição da erosão superficial: os autores ainda relatam que o princípio de funcionamento de um subsolador é a aplicação de uma força pela sapata metálica que promove o deslocamento do solo à sua frente, o que por sua vez promove a ruptura por cisalhamento. 
A ASAE (1982) define o subsolador como um implemento de preparo primário do solo, de utilização intermitente, operado em profundidades suficientes para romper as camadas de compactação subsuperficiais. Mialhe (1996) relata que a ASAE elaborou, em 1995, uma chave de classificação para máquinas de preparo de solo (Tabela 1).

Srivastava et al. (1993) afirmam que os subsoladores são utilizados para atravessar e romper camadas de solo impermeáveis ou compactadas e promover a infiltração da água. Os subsoladores são caracterizados por hastes que podem ser operadas em profundidades de 0,45 a $0,75 \mathrm{~m}$, ou mais, promovendo pouca mistura e nenhuma inversão de solo, sendo mais eficientes em condições de pouca umidade do solo. Observações realizadas por Cassel (1979), também mostraram que os maiores benefícios da subsolagem são observados principalmente nos anos que deficiências hídricas mais severas são constatadas.

Os subsoladores são implementos utilizados sob a superfície do solo para promover a desagregação de camadas compactadas, a fim de facilitar a penetração de raízes e da água para as camadas mais profundas do solo (Balastreire, 1987). Para o autor, os subsoladores requerem alta potência para sua utilização, pois trabalham em profundidades que podem chegar a até $0,80 \mathrm{~m}$. Além disso, deve-se ter conhecimento suficiente sobre as características do solo trabalhado, tais como compactação existente, teor de umidade, cobertura existente na superfície, textura e estrutura e, ainda, sobre as características necessárias para a operação com o equipamento, como profundidade de trabalho, espaçamento 
entre hastes, potência necessária, dimensões e formatos das hastes para que os subsoladores sejam usados corretamente.

Tabela 1. Chave de classificação para máquinas de preparo de solo.

1. Máquinas de preparo primário do solo ("primary tillage")

1.1. Arados

1.1.1. Aivecas

1.1.2. Cinzel ou escarificador

1.1.3. Combinação de cinzel com discos cortantes

1.1.4. Lâminas cortantes sub-superficiais

1.1.5. Discos

1.1.6. Canteiradores

1.2. Aivecas sulcadoras

1.3. Discos canteiradores

1.4. Subsoladores

1.5. Grades de discos

1.5.1. Discos em "off-set" ou em "V"

1.5.2. Discos em "tandem" ou em duplo "V" ou, ainda, em "X"

2. Máquinas de preparo secundário do solo ("secondary tillage")

2.1. Grades

2.1.1. Discos

2.1.2. Molas, dentes, ponteiras, rolo ou hastes

2.1.3. Facas

2.1.4. Dentes oscilantes acionados pela TDP

2.1.5. Rolos cônicos

2.1.6. Camalhadora

2.1.7. Niveladora

2.1.8. Rotativa com auto-acionamento

2.2. Cultivadores

2.2.1. Mecânicos de hastes

2.2.2. Capinadores de hastes

2.2.3. Rolos

2.2.4. Enxadas rotativas-acionadas pela TDP

$2 \cdot 2 \cdot 5$. Canteiradores

2.2.6. Destorroadores denteados rotativos

3. Máquinas de cultivo do solo

4. Máquinas para operações conjugadas com preparo primário

5. Máquinas para operações conjugadas com preparo secundário 


\begin{abstract}
Gadanha Júnior et al. (1991) definem o subsolador como um implemento que mobiliza o solo em profundidade, rompendo camadas compactadas que dificultam a penetração de raízes e a infiltração de água, melhorando a aeração do solo e a movimentação de água em seu perfil, diminuindo os riscos de erosão.
\end{abstract}

Segundo Balastreire (1987), os subsoladores são constituidos de:

- barra porta-ferramentas, montada no sistema hidráulico de levantamento dos tratores, ou de arrasto, quando possui uma barra de tração para acoplamento no trator;

- haste, constituída de uma barra de aço plana, com formato que varia em função do fabricante. Normalmente o formato da haste é reto, curvo ou parabólico. Como a haste é o principal elemento de corte do solo até a profundidade de trabalho da ponta, seu formato tem grande influência na força de tração necessária para a operação;

- ponta, elemento que se desloca sob a superfície do solo, realizando a desagregação de um volume de solo na sua frente. Esse volume de solo é função do teor de umidade do mesmo. Se o solo estiver com umidade excessiva, a ponta e a haste apenas cortam o solo, sem desagregá-lo;

- rodas de controle de profundidade, usadas quando 0 implemento é de arrasto, podendo ser de metal ou com aro e pneu. 
Mialhe (1996) afirma que a mobilização do solo por desagregação sub-superficial é típica do subsolador, onde - órgão ativo, disposto na extremidade inferior de uma coluna, atua nas camadas sub-superficiais, rompendo a massa de solo à frente e lateralmente, desagregando o perfil de baixo para cima.

Dentre os vários parâmetros que interagem na operação de subsolagem, Telischi et al. (1956) destacam a força de tração, que pode variar em função do teor de água e argila do solo, velocidade de deslocamento do trator e implemento e, também, da intensidade de compactação e profundidade da camada compactada.

Um parâmetro constituinte dos subsoladores que gera bastante polêmica é a configuração da haste subsoladora. Silva et al. (1984a), ao testar diferentes configurações de peças ativas de subsoladores (reta, curva e parabólica), concluiram que a geometria não apresentou influência significativa na operação dos subsoladores avaliados. Mas, ao trabalhar num latossolo roxo, com teor médio de umidade da ordem de 19,5\%, Lanças (1988) observou que as hastes parabólicas demandaram maior força de tração que a haste reta-inclinada. O autor, ao estudar $\circ$ tipo de haste, observou, ainda, que a potência na barra de tração em hastes reta-inclinadas foi significativamente menor em relação às hastes parabólicas.

Spoor \& Godwin (1978) observaram que a colocação de asas de 0,42 m de largura no subsolador aumentou em 40\% a força de tração e duplicou a área transversal de solo mobilizado, resultando em significativa redução da 
resistência especifica do solo, quando comparado com 0 subsolador sem asa. As larguras de asas utilizadas, 0,30 m e $0,42 \mathrm{~m}$, não ocasionaram efeitos significativos na força de tração nem na resistência específica do solo. Resultados semelhantes foram obtidos por Lanças (1988), ao observar que nas hastes com ponteiras sem asa a força de tração foi significativamente menor que nas ponteiras com asa. Ao interagir o tipo de haste com o tipo de ponteira, o autor também verificou que ponteiras com asa requerem mais potência na barra de tração do que as ponteiras sem asa, para todos os tipos de hastes.

Avaliando especificamente o parâmetro asa, Souza (1989) estudou a influência de parâmetros geométricos na distribuição das forças, em um solo de textura argilosa (teor de argila $=57 \%, U=20 \%$ e $\mathrm{Dg}=1,25 \mathrm{~g} \mathrm{~cm}^{-3}$ ), em trabalho desenvolvido com subsolador de haste única curva e espessura de uma polegada. O autor concluiu que:

- a força horizontal, que atua sobre a ferramenta no sentido contrário ao deslocamento do trator, tendeu a aumentar de intensidade quando a largura da asa passou de 0,24 m para $0,435 \mathrm{~m}$, e também quando o ângulo de envergadura passou de $0^{\circ}$ para $24^{\circ}$;

- a força vertical atuando sobre a ferramenta no sentido da superfície para baixo, isto é, auxiliando a penetração da ferramenta no solo, tendeu a diminuir de intensidade quando a largura da asa passou de 0,24 m para 0,435 m. Em relação ao ângulo de envergadura da asa, não houve diferença significativa entre os tratamentos para a força vertical; 
- não foi verificada influência significativa do ângulo de ataque da asa em relação às forças horizontais e verticais. Em relação à área de solo mobilizado para os diferentes ângulos de ataque da asa, não houve diferenças estatísticas entre os diferentes ângulos testados $\left(15^{\circ}, 25^{\circ}\right.$ e $\left.35^{\circ}\right)$, sendo que $\circ$ acréscimo máximo na área transversal em relação à ponta sem asa, foi de 53\% correspondente ao ângulo de $15^{\circ}$.

Segundo Fernandes (1985), o ângulo de fixação de aletas (ou asas) em relação ao plano horizontal é fundamental para o bom desempenho do equipamento, seja do ponto de vista do trabalho executado, como do requerimento e potência. O autor ainda ressalta que o ângulo deve estar correlacionado com a largura da aleta, estando em torno de 15 a $20^{\circ}$. Quanto à forma e dimensão da aleta, o autor afirma que aletas com $10 \mathrm{~cm}$ de largura tiveram melhor desempenho sob 0 ponto de vista de fragmentação do solo. Acompanhando este raciocínio, Rípoli et al. (1985) mostraram que aletas posicionadas a ângulos maiores do que $25^{\circ}$ fazem aumentar excessivamente o requerimento de esforço tratório, enquanto que ângulos menores do que $10^{\circ}$ praticamente não refletem na melhoria do preparo do solo pelo subsolador. Os ângulos das aletas entre 15 e $20^{\circ}$ foram os que apresentaram os resultados mais satisfatórios.

Estudando mais detalhadamente $\circ$ ângulo de ataque, Payne \& Tanner (1959), em experimentos realizados em laboratório e no campo, com uma larga gama de ferramentas planas retangulares, com várias larguras e ângulos de ataque, concluíram que: 
- a eficiência das ferramentas, medida em termos de força por unidade de largura de solo mobilizado, variou com as proporções da ferramenta mas foi extremamente sensível à variação do ângulo de ataque da mesma, sendo aproximadamente 8 vezes superior em um ângulo de ataque de $20^{\circ}$ em relação a um ângulo de $160^{\circ}$;

- ângulos de ataque da ferramenta entre $20^{\circ}$ e $50^{\circ}$ pouco afetaram o valor da força de tração, mas além de $50^{\circ}$ esta aumentou rapidamente chegando a ser, a $160^{\circ}, 5$ vezes superior à força correspondente ao ângulo de $20^{\circ}$;

- para ferramentas com ângulo de ataque inferior a 45, a reação do solo, que é a componente vertical da força, auxilia na penetração da ferramenta no solo; mas, com ângulos superiores essa reação opõe-se a penetração da ferramenta.

\begin{abstract}
Resultados semelhantes são citados por O'Callaghan \& McCullen (1965) que, em testes realizados no campo, com ferramentas planas retangulares e planas com cunhas, variando o ângulo de ataque concluíram que:
\end{abstract}

- a componente vertical da força atuando sobre a ferramenta diminui gradualmente até zero e eventualmente inverte sua direção na medida em que o ângulo de ataque diminui, confirmando os resultados - encontrados por outros pesquisadores;

- a resistência específica (força/área de solo mobilizado) diminui com a redução do ângulo de ataque. 
A textura do solo também mostrou-se contundente nos resultados relativos à força de tração na subsolagem, como mostraram Dransfield et al. (1965), ao avaliar ferramentas planas retangulares em campos de plantio de trigo na Austrália. Os autores puderam concluir que:

- em solos soltos (desagregados) a força de tração em uma ferramenta vertical aumenta linearmente com a profundidade de trabalho, mas em solos com maior densidade essa linearidade deixa de existir para a força horizontal e somente a força vertical mantém essa característica;

- em solos soltos, a força de tração para ferramentas verticais é pouco afetada para uma variação de velocidade de até $8 \mathrm{~km} \mathrm{~h} \mathrm{~h}^{-1}$ mas em solos mais compactados a força aumenta de 10 a $15 \%$ a cada $1,6 \mathrm{~km} \mathrm{~h} \mathrm{~h}^{-1}$. Forças verticais mantém-se razoavelmente constantes quando a velocidade é variada;

- a força de tração diminui com o decréscimo do ângulo de ataque da ferramenta. O efeito mais benéfico da diminuição do ângulo é encontrado a $45^{\circ}$ para solos soltos, mas para solos mais compactados é encontrado em ângulos menores. A força vertical cai para zero a $45^{\circ}$ e inclusive pode inverter o sentido para ângulos menores.

Resultados obtidos por Stafford (1979)

confirmam as observações de Dransfield et al. (1964), ao realizar testes em dois tipos de solo, um arenoso e outro argiloso, com variações nos teores de umidade e velocidade. 
As ferramentas utilizadas foram planas retangulares com dois ângulos de ataque, $45^{\circ}$ e $90^{\circ}$, verificando que para todas as condições de solo a força de tração aumentou com a velocidade. Houve evidência de que a força de tração diminuiu com a redução do ângulo de ataque da ferramenta. Mas, a taxa de aumento também está relacionada com o teor de umidade do solo, o que Santos Filho (1993) confirma ao concluir que solos mais secos exigem maior esforço tratório, porém a força de tração diminui com o aumento do teor de água no solo até um certo limite, a partir do qual volta a subir.

Para Cassel (1979), os solos úmidos exigem menos potência para tracionar o subsolador, até um certo limite. No entanto, a mobilização do solo, quando este é preparado úmido, é menor, quando comparada com a realizada em solo seco. O autor ainda ressalta que a subsolagem deve ser realizada, de preferência, quando o solo está friável, o que jmplica em necessidades de tração relativamente mais altas. Rípoli et al. (1985) também concordam que para que a subsolagem seja eficiente, o solo a ser subsolado deve conter baixos teores de umidade, a fim de não se correr o risco de aumentar a compactação já existente, pelo próprio tráfego de fonte de potência ou pelo órgão ativo do subsolador.

Garner et al. (1987) também verificaram que o tipo de solo e a umidade são fatores que influenciam os resultados de desempenho dos subsoladores, ao ensaiar com cinco tipos diferentes de solos da planície costeira dos Estados Unidos. Os autores observaram que a força de tração aumentou nos solos com horizonte B mais próximo à superfície. Beltrame (1983), trabalhando com três tipos de subsoladores comerciais com características construtivas distintas, 
concluiu que a subsolagem é mais eficiente quando executada em umidade do solo abaixo do limite inferior de plasticidade.

Resultados preliminares em relação à influência da velocidade de deslocamento na força de tração foram alcançados por Siemens et al. (1965) ao testar em caixa de solo com diversas ferramentas e vários ângulos de ataque. os autores observaram que a componente horizontal da força aumentou com a velocidade para todas as ferramentas testadas. Confirmando estes resultados, stafford (1974) concluiu que quanto maior a velocidade, maior a força de tração exigida.

Em relação à razão força de tração/profundidade, Payne (1956), em experimentos realizados em laboratório e no campo, com ferramentas verticais planas retangulares com razão entre profundidade e largura de 25:1 a 1:1, denominadas ferramentas estreitas, verificou que:

- a força de tração varia linearmente com a profundidade de trabalho;

- o solo rompe-se em sucessivas camadas e o registro da força de tração apresenta-se na forma de uma onda, devido aos valores máximos atingidos na ruptura e os valores mínimos, que chegam a 30\% do valor máximo.

Siemens et al. (1965) confirmaram esta última observação, ao registrar que -a propagação das forças apresentou a forma de onda, sendo isto devido ao processo de ruptura do solo que ocorre em camadas sucessivas. 
Bicudo (1990), ao ensaiar com subsoladores de 1, 2 e 3 hastes em diferentes profundidades de trabalho e tamanho de sapata, em Terra Roxa Estruturada (U = 19\%), operando com o trator na mesma marcha (trator $\mathrm{MF}-296, \mathrm{P}=$ $118 \mathrm{CV}$ no motor) e com a mesma rotação no motor, observou que a força de tração média aumentou significativamente para as profundidades acima de $0,3 \mathrm{~m}$, indicando um esforço tratório maior para profundidades mais elevadas. Outra informação importante foi fornecida por Beltrame (1983), ao afirmar que a profundidade de trabalho recomendada deve ser por volta de cinco a sete vezes a largura da ponteira.

Em termos de velocidade média de deslocamento e tipo de haste utilizada pode-se citar o estudo realizado por Lanças (1988), no qual o autor relata que a velocidade média de deslocamento para a haste reta-inclinada foi significativamente maior do que a velocidade obtida para as hastes parabólicas. Já em relação ao tipo de ponteira, o autor observou que hastes munidas de ponteiras sem asa resultaram em velocidades significativamente maiores em relação às hastes munidas de ponteiras com asa. o autor também constatou que a capacidade de campo efetiva (ha/h) não forneceu resultados significativamente diferentes para as hastes reta-inclinada e parabólica. Mas, ao analisar o tipo de ponteira, o autor verificou que a ponteira com asa apresentou resultados significativamente melhores em relação à ponteira sem asa, quando avaliadas em termos de rendimento operacional (área mobilizada de solo/tempo de preparo). Ainda pode-se citar que aumentando-se o número de hastes, há também um aumento da capacidade de campo efetiva (ha/h), como mostram os estudos realizados por Bicudo (1990). 
Lanças \& Benez (1989) desenvolveram um trabalho com três tipos de hastes, duas parabólicas e uma reta inclinada a $45^{\circ}$, verificando que os dois tipos de hastes parabólicas apresentaram maior mobilização do solo em relação à haste reta inclinada e esta apresentou a menor força média de tração. A resistência específica operacional (força/área média de mobilização do solo) apresentou diferença significativa entre as duas hastes parabólicas. 


\section{MATERIAL E MÉTODOS}

o ensaio foi conduzido nas Fazendas Água Bonita, localizada no Município de Itatinga e Santa Terezinha, localizada no Município de Paranapanema, ambas no estado de São Paulo. Foram usadas áreas em reforma, após cultivo de povoamentos de Eucalyptus grandis, manejadas no sistema de cultivo mínimo do solo. O solo da Fazenda Água Bonita foi caracterizado como Neossolo Quartzarênico (RQ) e o da Fazenda Santa Terezinha, como Latossolo Vermelho-Amarelo (LVA) textura média, segundo EMBRAPA (1999) (Tabelas 2 e 3).

O povoamento da Fazenda Água Bonita (RQ) foi cultivado no espaçamento de $3 \times 2 \mathrm{~m}$ e a colheita realizada por "sling-shots" e "harvesters" e, o baldeio, por "skidders". Esse povoamento, anterior à instalação do ensaio, estava em primeira rotação. O povoamento da Fazenda Santa Terezinha (LVA) foi cultivado no espaçamento de $3 \times 2 \mathrm{~m}$ e estava na segunda rotação. A colheita foi realizada por "harvesters" e, o baldeio, por "forwarders". As duas áreas eram planas, com declividade média inferior a $3 \%$. 


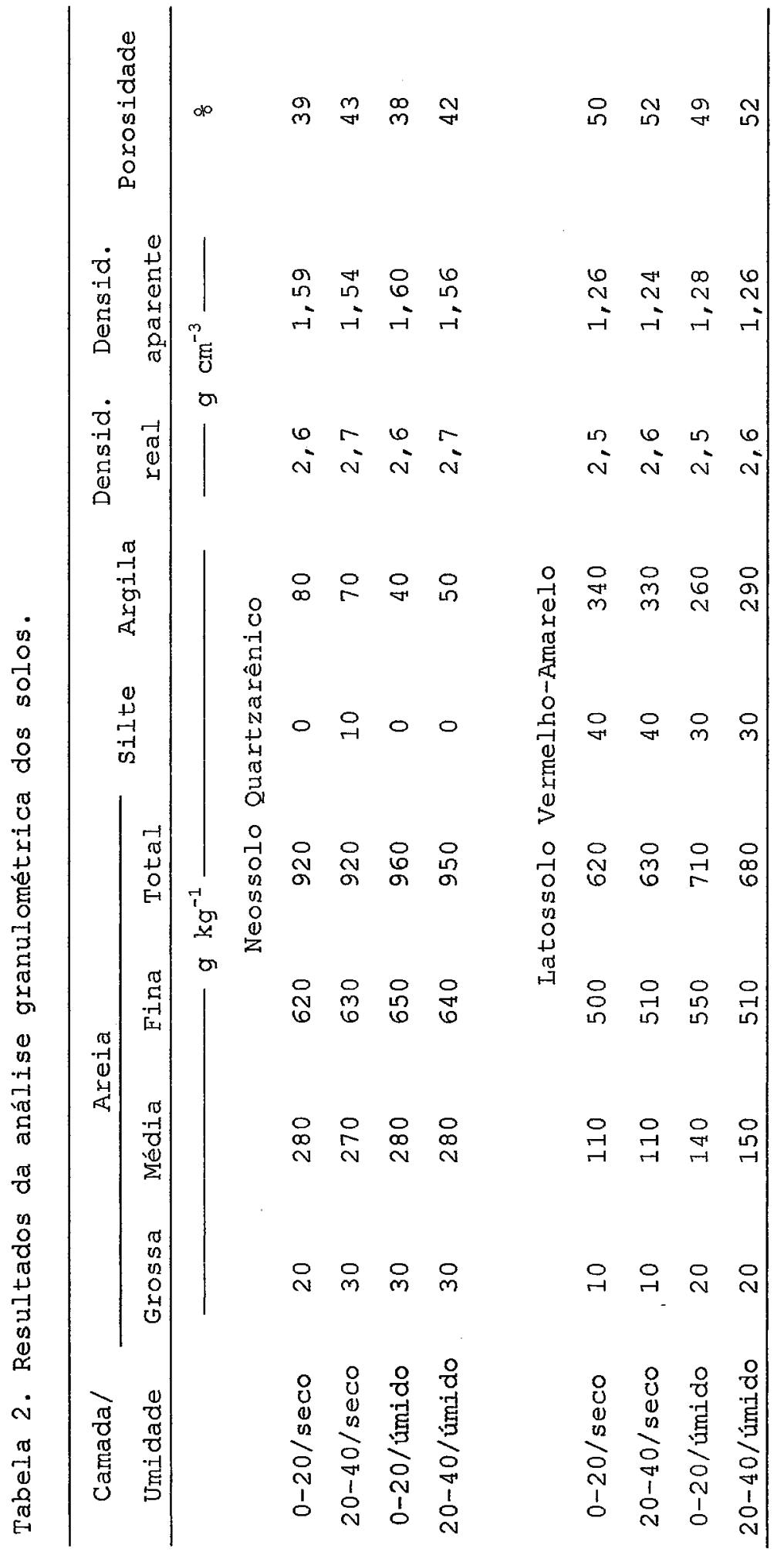




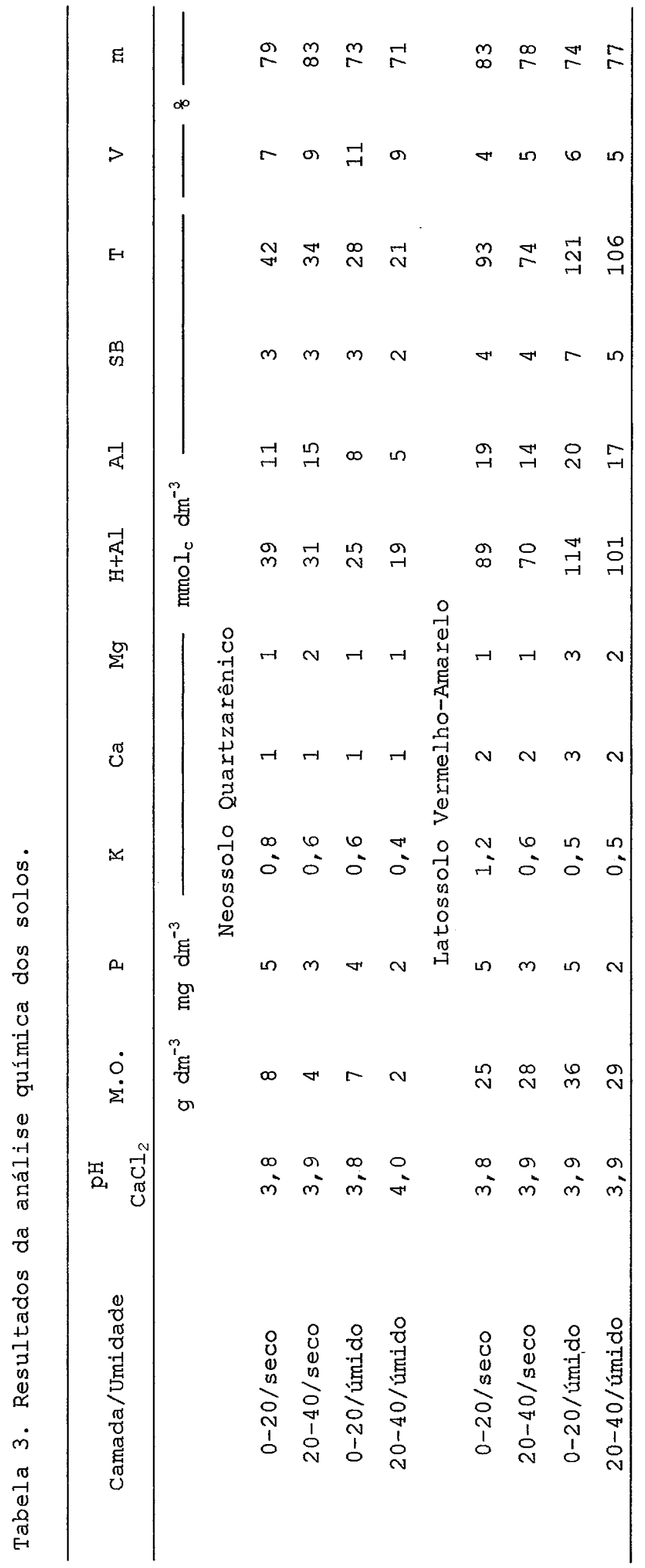


A determinação dos tipos e configurações de hastes e ponteiras para o estudo baseou-se numa revisão bibliográfica sobre artigos científicos específicos sobre o tema. Foram estabelecidos dois tipos de ponteiras, uma com asa e a outra sem asa (Figura 1) e, três configurações de hastes, duas parabólicas e uma reta com inclinação de $45^{\circ}$ com a horizontal (Figura 2). As hastes $e$ as ponteiras foram fabricadas numa empresa siderúrgica, especializada em implementos agrícolas e florestais.
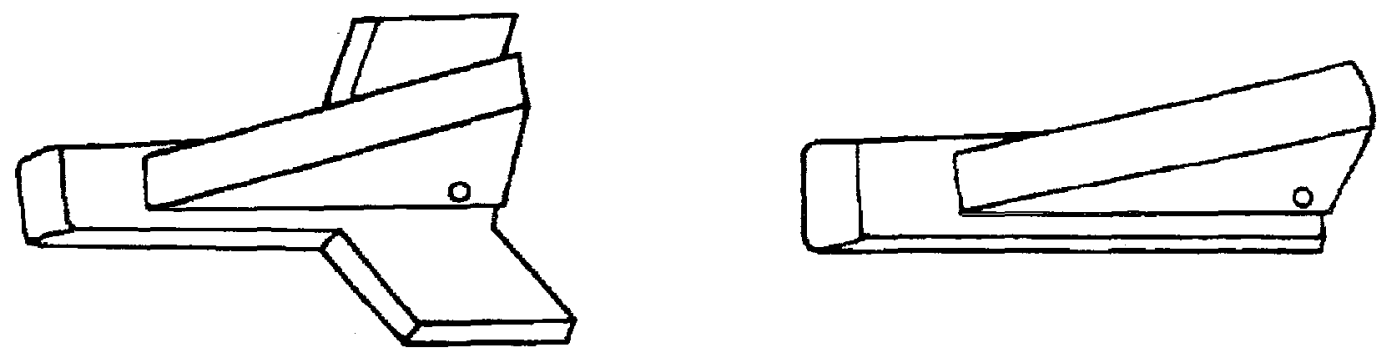

Figura 1. Ponteiras avaliadas no ensaio. 

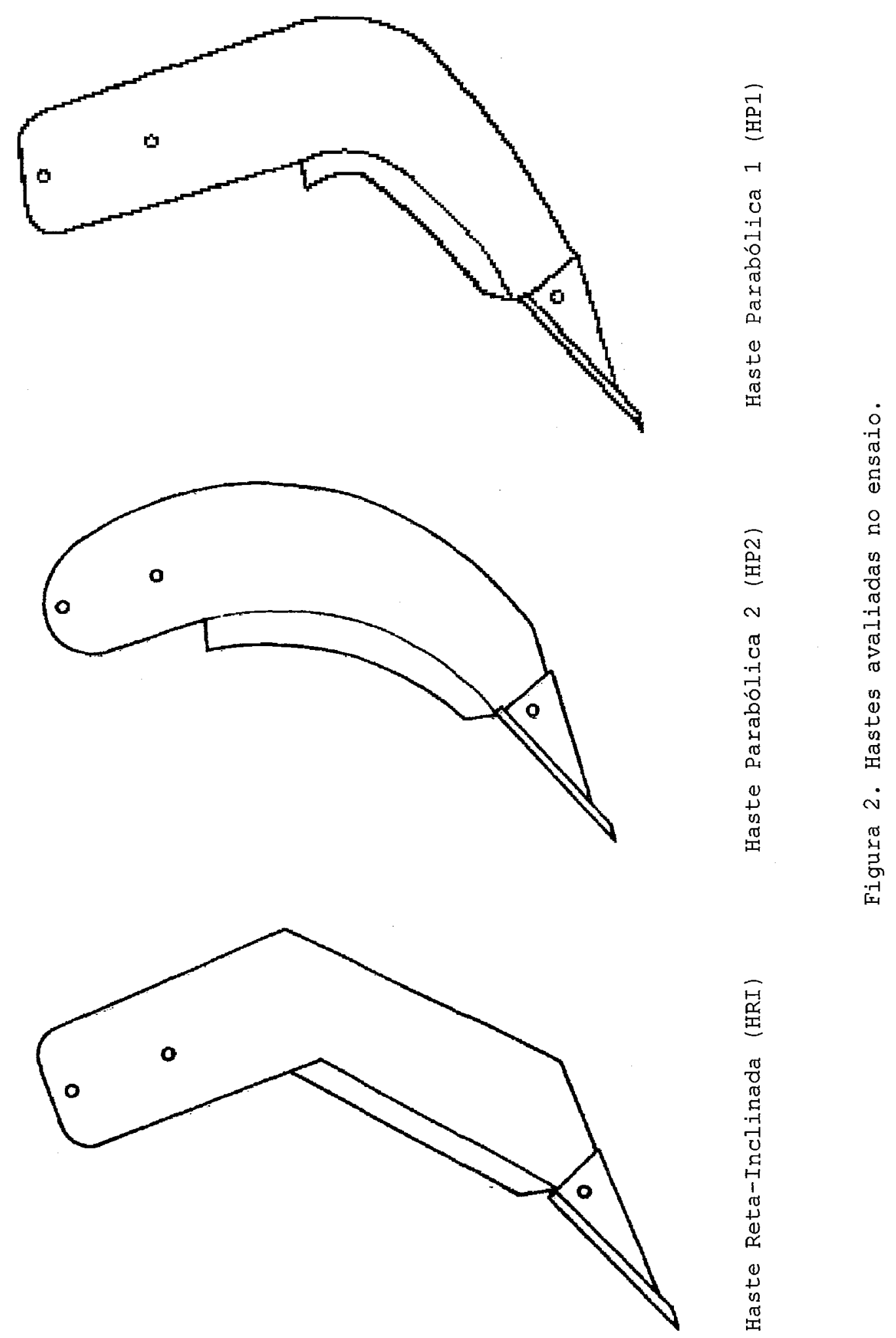
$\mathrm{Na}$ Tabela 4 estão relacionados os diferentes tipos de hastes e ponteiras estudados. Os subsoladores testados possuem haste única, com controle de profundidade por braçadeira de fixação. Na frente das hastes foi usado um disco cortante preso à barra porta-ferramenta, com a finalidade de cortar os residuos vegetais. As hastes foram fabricadas com chapas de aço de uma polegada $(25,4 \mathrm{~mm})$, possuindo em sua parte interior lâminas afiadas para facilitar o rompimento das camadas de solo. Na ponta das hastes foram avaliadas as ponteiras com e sem asa. A regulagem da profundidade de trabalho foi realizada em alguns testes iniciais, ao lado da área experimental.

Segundo Mialhe (1996), o ensaio de máquinas montadas no engate de três pontos de tratores agrícolas pode ser realizado utilizando-se dinamômetros especiais que são montados em uma estrutura projetada exclusivamente para esse fim, como descrita por Ferretti (1992). Esta estrutura é equipada com seis células de carga, ou pelo sistema denominado de comboio (ou método indireto). Dada a especificidade do equipamento e o pouco tempo de uso no ensaio, o método descrito por Ferreti (1992) iria onerar e inviabilizar o estudo, razão pela qual a determinação da força de tração foi realizada pelo método indireto.

Para isto, foram usados dois tratores conectados. O primeiro, denominado trator de tração ( $T_{T}$ ), tracionou o segundo, trator suporte $\left(T_{S}\right)$, o qual realizava o preparo de solo (Figura 3). Os tratores foram conduzidos em marcha ( $3^{a}$ marcha reduzida) e rotação do motor $(1700 \mathrm{rpm}$ ) constantes. Entre os tratores foi colocada uma célula de carga Kyowa Electronic Instruments Co., com capacidade de 
Tabela 4. Descrição dos tratamentos experimentais.

\begin{tabular}{|c|c|c|c|c|c|}
\hline Tratamento & Solo & $\begin{array}{l}\text { Umidade } \\
\text { do solo }\end{array}$ & Tipo de haste & Ponteira & $\begin{array}{l}\text { Profundidade } \\
\text { de trabalho }\end{array}$ \\
\hline & & & & & $\mathrm{cm}$ \\
\hline 1 & LVA & seco & parabólica 1 & sem asa & 20 \\
\hline 2 & LVA & úmido & parabólica 1 & sem asa & 20 \\
\hline 3 & $\mathrm{RQ}$ & seco & parabólica 1 & sem asa & 20 \\
\hline 4 & $\mathrm{RQ}$ & úmido & parabólica 1 & sem asa & 20 \\
\hline 5 & LVA & seco & parabólica 1 & com asa & 40 \\
\hline 6 & LVA & úmido & parabólica 1 & com asa & 40 \\
\hline 7 & $\mathrm{RQ}$ & seco & parabólica 1 & com asa & 40 \\
\hline 8 & $\mathrm{RQ}$ & úmido & parabólica 1 & com asa & 40 \\
\hline 9 & LVA & seco & parabólica 1 & sem asa & 40 \\
\hline 10 & LVA & úmido & parabólica 1 & sem asa & 40 \\
\hline 11 & $\mathrm{RQ}$ & $\operatorname{seco}$ & parabólica 1 & sem asa & 40 \\
\hline 12 & $\mathrm{RQ}$ & úmido & parabólica 1 & sem asa & 40 \\
\hline 13 & LVA & seco & reta-inclinada & com asa & 40 \\
\hline 14 & LVA & úmido & reta-inclinada & com asa & 40 \\
\hline 15 & $\mathrm{RQ}$ & seco & reta-inclinada & com asa & 40 \\
\hline 16 & $\mathrm{RQ}$ & úmido & reta-inclinada & com asa & 40 \\
\hline 17 & LVA & $\operatorname{seco}$ & reta-inclinada & sem asa & 40 \\
\hline 18 & LVA & úmido & reta-inclinada & sem asa & 40 \\
\hline 19 & $\mathrm{RQ}$ & seco & reta-inclinada & sem asa & 40 \\
\hline 20 & $\mathrm{R} Q$ & úmido & reta-inclinada & sem asa & 40 \\
\hline 21 & LVA & seco & parabólica 2 & sem asa & 40 \\
\hline 22 & LVA & úmido & parabólica 2 & sem asa & 40 \\
\hline 23 & $\mathrm{RQ}$ & seco & parabólica 2 & sem asa & 40 \\
\hline 24 & $\mathrm{RQ}$ & úmido & parabólica 2 & sem asa & 40 \\
\hline
\end{tabular}


49000 N. Para se determinar a resistência ao rolamento do conjunto trator/implemento, fizeram-se medições da força de tração sem a ação dos implementos de preparo de solo. A força de tração foi estimada pela diferença entre os valores obtidos com os implementos em e fora de operação. Os aparelhos usados para medir a força de tração e a patinagem foram instalados num trator modelo MF-296, marca Massey Ferguson, com peso aproximado de $5,7 t\left(T_{T}\right)$. O trator usado no preparo de solo é do modelo 6500, marca Valmet, com peso aproximado de $6,0 \mathrm{t}\left(\mathrm{T}_{\mathrm{S}}\right)$.

Célula de carga

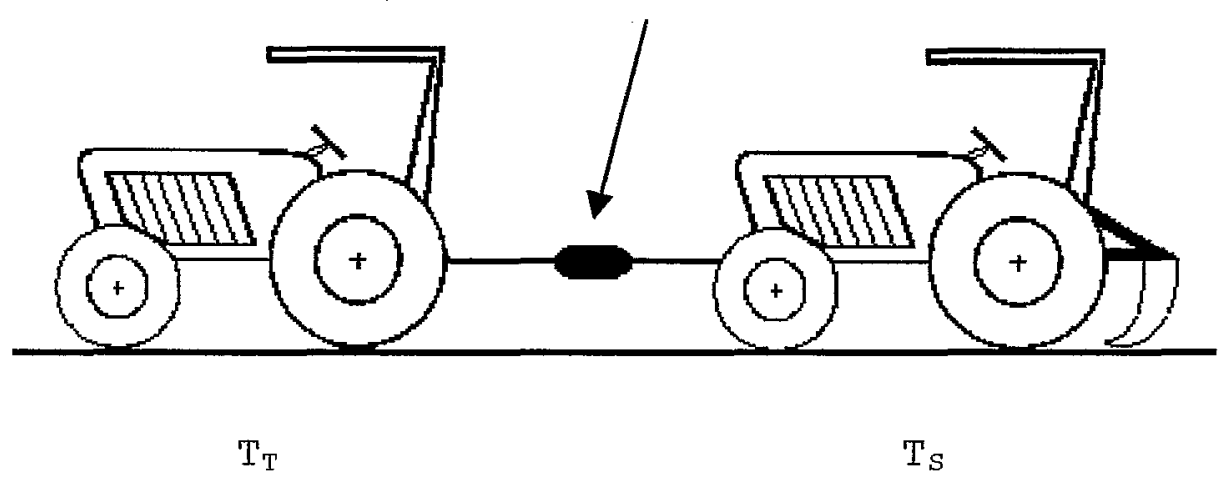

Figura 3. Método indireto de determinação da força de tração em máquinas acopladas ao engate de três pontos. 
Os diferentes tratamentos foram aplicados em duas estações distintas: inverno (solo seco) e verão (solo úmido). O teor de água do solo foi avaliado por coletas aleatórias, de quatro amostras de solo por parcela, nas profundidades de 0 a 20 e 20 a $40 \mathrm{~cm}$, no momento da realização do ensaio (Tabela 5). Utilizou-se o método gravimétrico para a determinação da umidade do solo (EMBRAPA, 1997).

Tabela 5. Teor de água dos solos.

\begin{tabular}{ccccc}
\hline \multirow{2}{*}{ Solo } & Umidade & \multicolumn{3}{c}{ Teor de água } \\
\cline { 3 - 5 } & do solo & $0-20 \mathrm{~cm}$ & $20-40 \mathrm{~cm}$ & Média \\
\hline \multirow{2}{*}{ RQ } & seco & 4,5 & o por massa & \\
RQ & úmido & 6,1 & 4,4 & 4,5 \\
LVA & seco & 3,4 & 5,2 & 5,7 \\
LVA & úmido & 17,7 & 3,1 & 3,3 \\
\hline
\end{tabular}

A resistência dinâmica do solo do povoamento anterior (antes de seu preparo) foi determinada com penetrômetro de impacto (Stolf et al., 1982). Em cada parcela foram amostrados quatro pontos, na linha e entrelinha de plantio do povoamento anterior, para a determinação da resistência dinâmica inicial (Figura 4). Após o preparo de solo, foram feitas três determinações por parcela da resistência dinâmica do solo, transversalmente ao sentido do sulco, em subpontos distantes. $10 \mathrm{~cm}$ entre si, como apresentado na Figura 5. Com isto foi possível calcular a área de solo mobilizada pelas hastes nos diferentes tratamentos aplicados. 

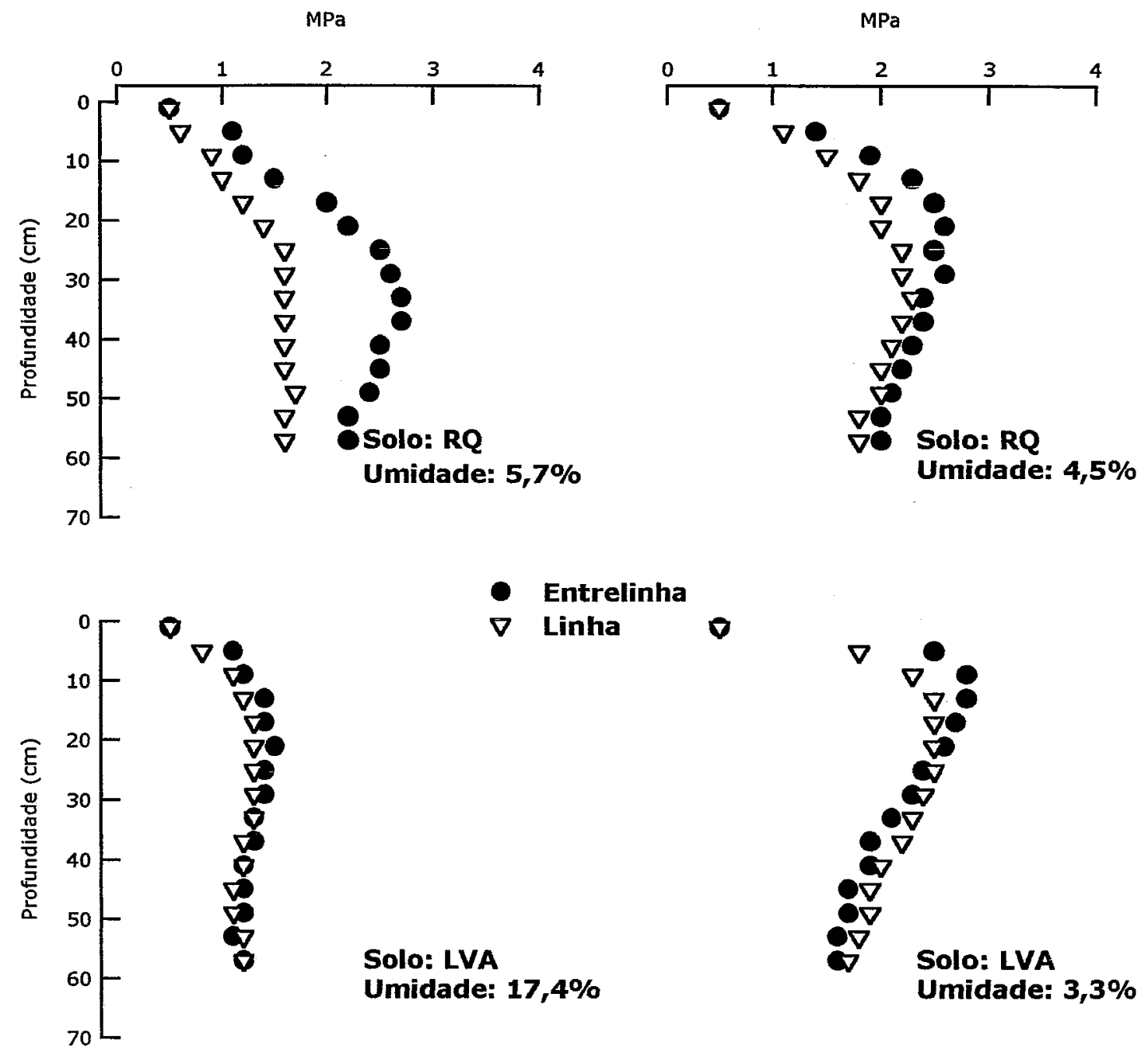

Figura 4. Resistência dinâmica inicial do $R Q$ e do LVA, úmidos e secos, na linha e entrelinha de plantio do povoamento anterior. 
a)

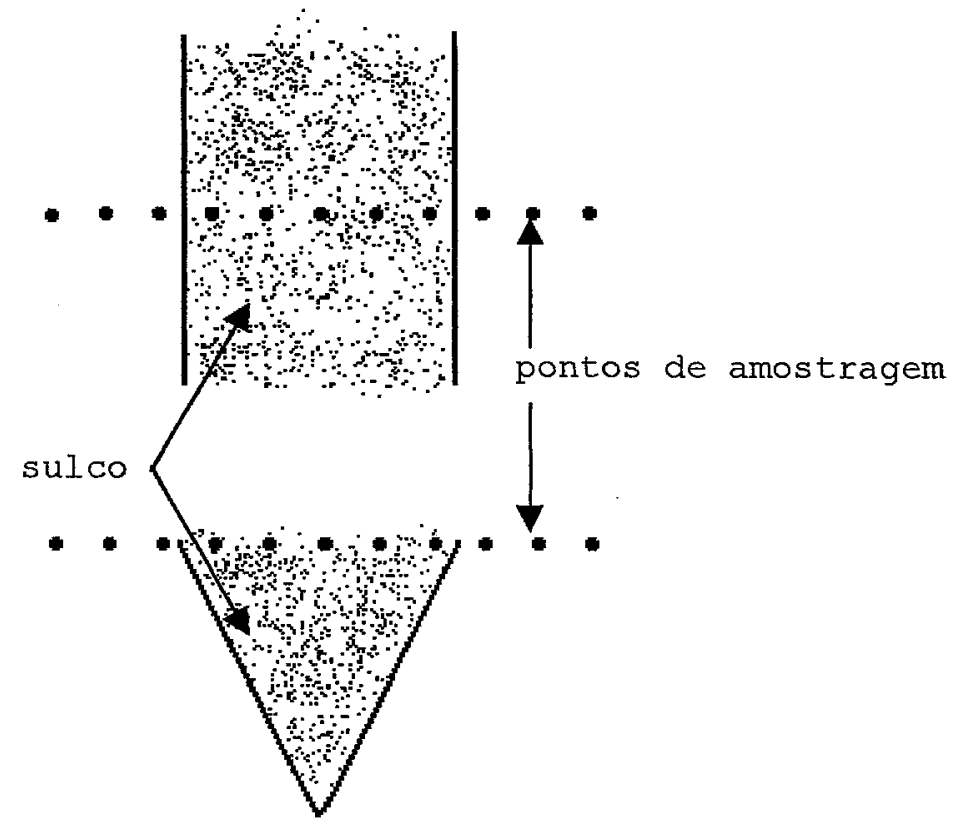

Figura 5. Esquema do perfil de solo mobilizado após a subsolagem: a) Vista de cima da faixa de solo preparado e b) Vista vertical da seção de solo preparado.

O delineamento experimental foi em blocos ao acaso, com quatro repetições. Cada parcela tinha $90 \mathrm{~m}^{2}, 30 \mathrm{~m}$ de comprimento por $3 \mathrm{~m}$ de largura, ou seja, a largura de ataque de cada linha de preparo de solo. Antes de cada parcela, foram reservados $15 \mathrm{~m}$ para a estabilização da velocidade de trabalho e profundidade de operação do subsolador. Dez metros após a parcela foram usados para manobras e outras operações.

A potência na barra de tração foi determinada conforme a seguinte equação: 


$$
\mathrm{PBT}=\frac{\mathrm{FT} \times \mathrm{VD}}{3600}
$$

Onde:

PBT é a potência na barra de tração (kW);

FT é a força de tração média $(N)$; e,

VD é a velocidade média de deslocamento $\left(\mathrm{km} \mathrm{h}^{-1}\right)$.

A resistência específica operacional, descrita como a força necessária para mobilizar um metro quadrado de solo, foi calculada através da equação:

$$
\mathrm{REO}=\frac{\mathrm{FT}}{\mathrm{ASM}}
$$

Onde:

REO é a resistência específica operacional $\left(\mathrm{N} \mathrm{m}^{-2}\right)$;

FT é a força de tração média $(N)$; e,

ASM é a área de solo mobilizada $\left(\mathrm{m}^{2}\right)$.

A patinagem das rodas motrizes foi determinada por sensores óticos elaborados no Departamento de Engenharia Rural da ESALQ, instalados nas rodas dianteira e traseira, à direita. Para a obtenção da patinagem em percentagem, utilizou-se a seguinte fórmula:

$$
\operatorname{PAT}\left(\frac{\circ}{\circ}\right)=\left(\frac{\text { leitura do } \mathrm{n}^{\circ} \text { de pulsos }- \text { calibração }}{\text { leitura do } \mathrm{n}^{\circ} \text { de pulsos }}\right) \times 100
$$


PAT é a patinagem (\%).

A velocidade média de deslocamento do conjunto trator/implemento foi avaliada de modo indireto, dividindo-se - tamanho da parcela experimental pelo tempo de percurso, medido por cronômetro. A seguinte equação foi usada:

$$
\mathrm{VD}=\frac{\mathrm{S}}{\mathrm{t}} \times 3,6
$$

Onde:

VD é a velocidade média de deslocamento $\left(\mathrm{km} \mathrm{h}^{-1}\right)$;

$\mathrm{S}$ é o espaço percorrido na parcela $(30 \mathrm{~m}) ; \mathrm{e}$,

$t$ é o tempo gasto no percurso (s).

A capacidade efetiva de trabalho (CET) foi obtida através da seguinte equação:

$$
\mathrm{CET}=\frac{V \times I}{10000} \times \mathrm{f}
$$

Onde:

CET é a capacidade efetiva de trabalho (ha $\mathrm{h}^{-1}$ );

$\mathrm{V}$ é a velocidade de trabalho $\left(\mathrm{m} \mathrm{h}^{-1}\right)$;

I é a largura de trabalho $(\mathrm{m})$; e, .

f é o coeficiente de eficiência. 


\section{RESULTADOS E DISCUSSÃO}

Similar aos resultados observados por Silva et al. (1984a), não houve diferença entre os tipos de hastes quanto a demanda por força de tração (Tabela 6). Estes resultados, provavelmente, se devem às condições de estrutura e textura dos solos, que têm estreita relação com suas resistências dinâmicas médias iniciais, medidas pelo penetrômetro de impacto: $1,8 \mathrm{MPa}$ para o $\mathrm{RQ}$ úmido, 2,0 $\mathrm{MPa}$ para o RQ seco, 1,2 MPa para o LVA úmido e 2,1 MPa para o LVA seco (Figura 4).

Os dois solos possuem altos teores de areia $\left(\mathrm{RQ}=940 \mathrm{~g} \quad \mathrm{~kg}^{-1}\right.$ e $\mathrm{LVA}=660 \mathrm{~g} \mathrm{~kg}^{-1}$ ) e mineralogia sexquioxídica, sem estrutura ou com estrutura do tipo granular e alto grau de friabilidade. Além disto, não possuem camadas compactadas, superficiais ou subsuperficiais. Caso os solos fossem mais argilosos e tivessem mineralogia que lhes conferisse maior dureza, seriam esperadas diferenças significativas entre as hastes quanto à necessidade de tração. Trabalhando num latossolo roxo, Lanças (1987), Lanças (1988) e Lanças \& Benez (1989) observaram que as hastes parabólicas demandaram maior força de tração que as hastes reta-inclinadas. 


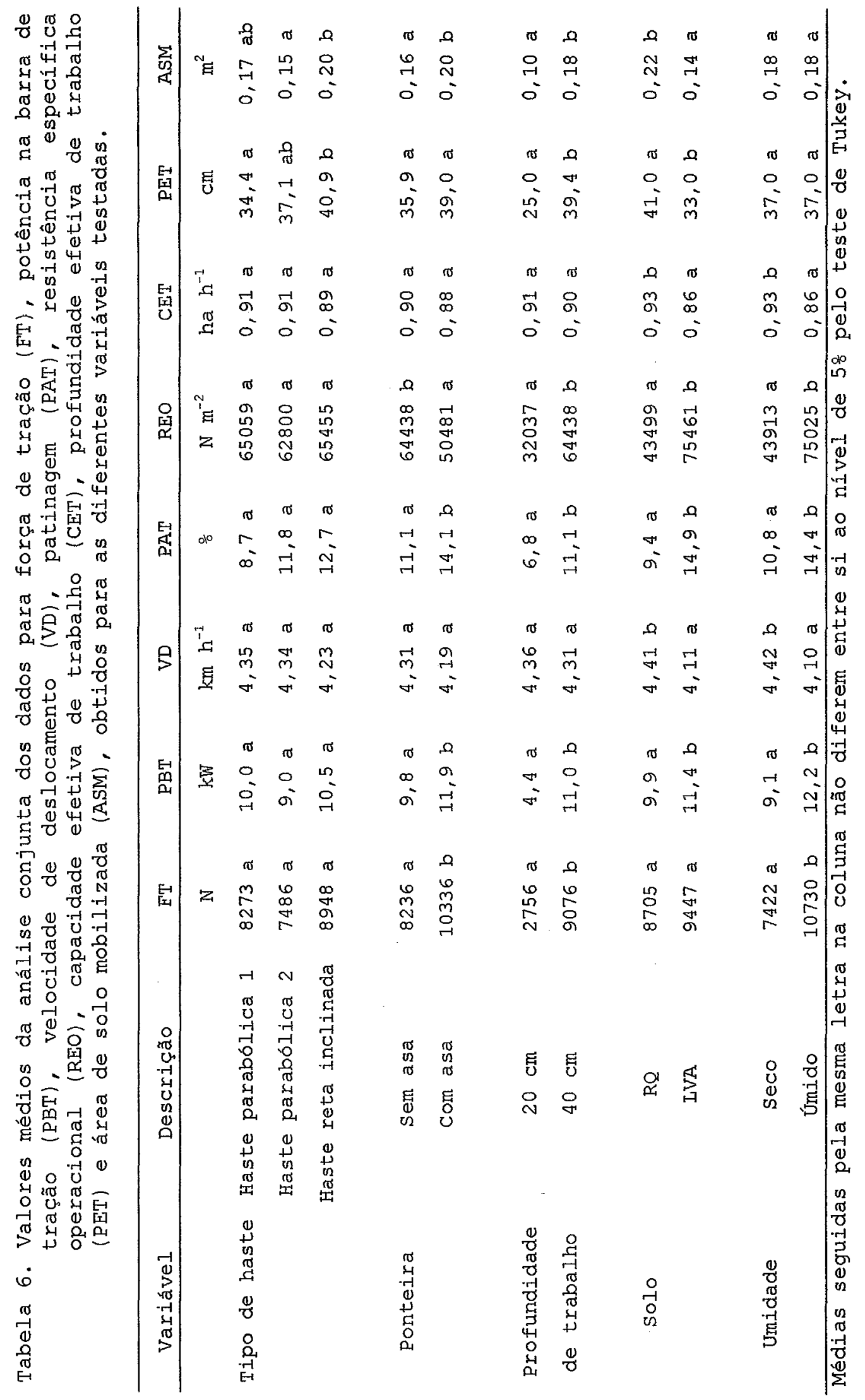


A força de tração foi medianamente correlacionada com a profundidade de trabalho $(r=0,60$; $\mathrm{p}<0,01)$, patinagem $(r=0,65 ; \mathrm{p}<0,01)$, capacidade efetiva de trabalho $(r=-0,40 ; p<0,01)$, velocidade de deslocamento $(r=$ $-0,40 ; \mathrm{p}<0,01)$ e a resistência especifica operacional ( $r=$ $0,58 ; \mathrm{p}<0,01) \quad($ Figura 6$)$.

Verificou-se que as ponteiras com asa exigiram cerca de $20 \%$ a mais de força de tração do que as ponteiras sem asa (Tabelas 6 e 7), sendo a maior área de contato entre a ponteira com asa e o solo a razão mais plausível para explicar este fato. Resultados semelhantes foram obtidos por Lanças (1987), Lanças (1988) e Spoor \& Godwin (1978). Bentivenha (2000) verificou que as ponteiras com asa, apesar de aumentarem a área e volume de solo mobilizado, não afetaram o ritmo de crescimento inicial do eucalipto.

Com o aumento da profundidade de trabalho de 20 para $40 \mathrm{~cm}$, a força de tração aumentou $70 \%$ e a potência na barra de tração 60\% (Tabelas 6 e 8), devido à maior área de solo mobilizada. Bicudo (1990), Payne (1956) e Silva et al. (1984b) também observaram que sulcos de menor profundidade demandaram menos força de tração que sulcos mais profundos. 

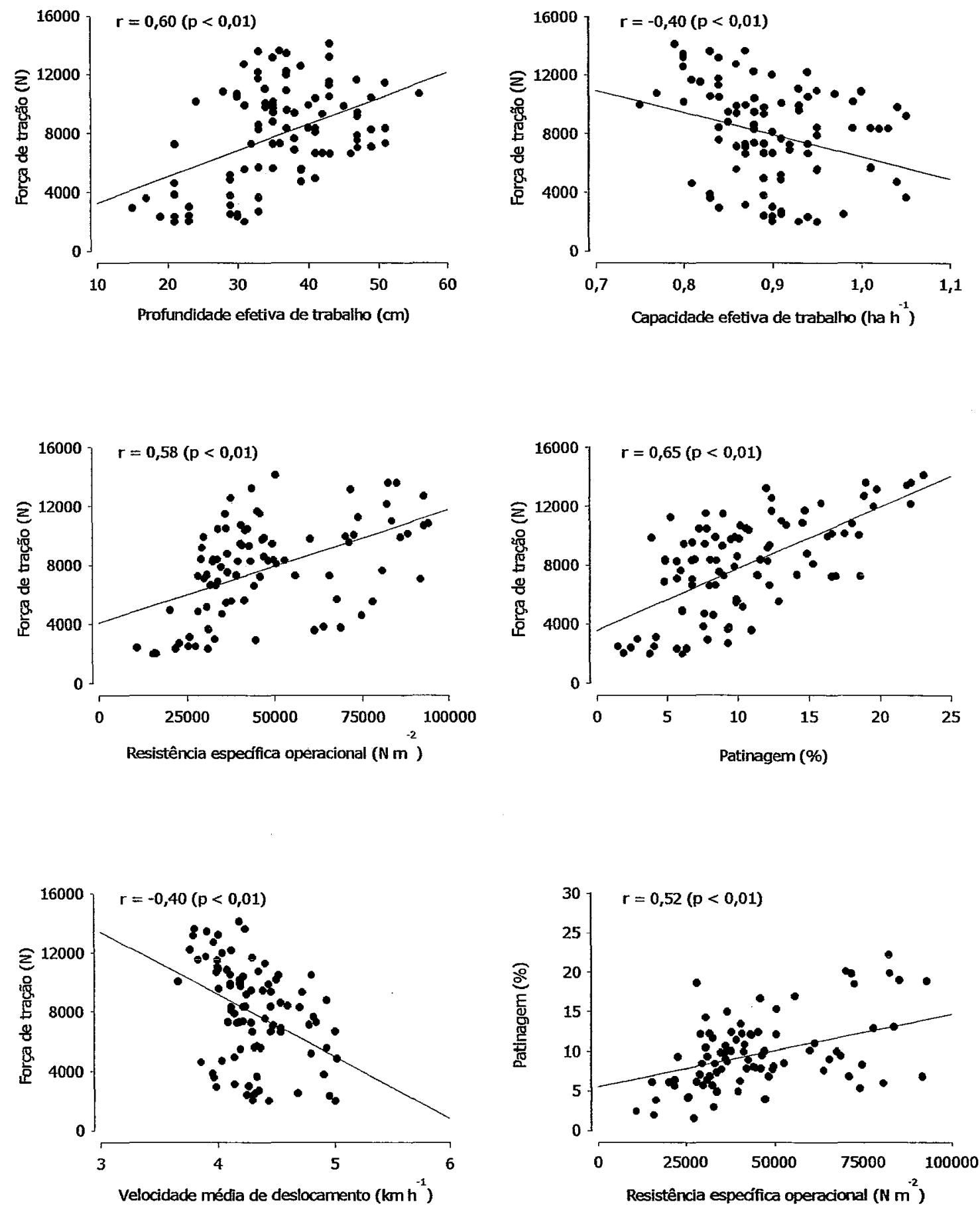

Figura 6. Correlação entre algumas variáveis estudadas. 


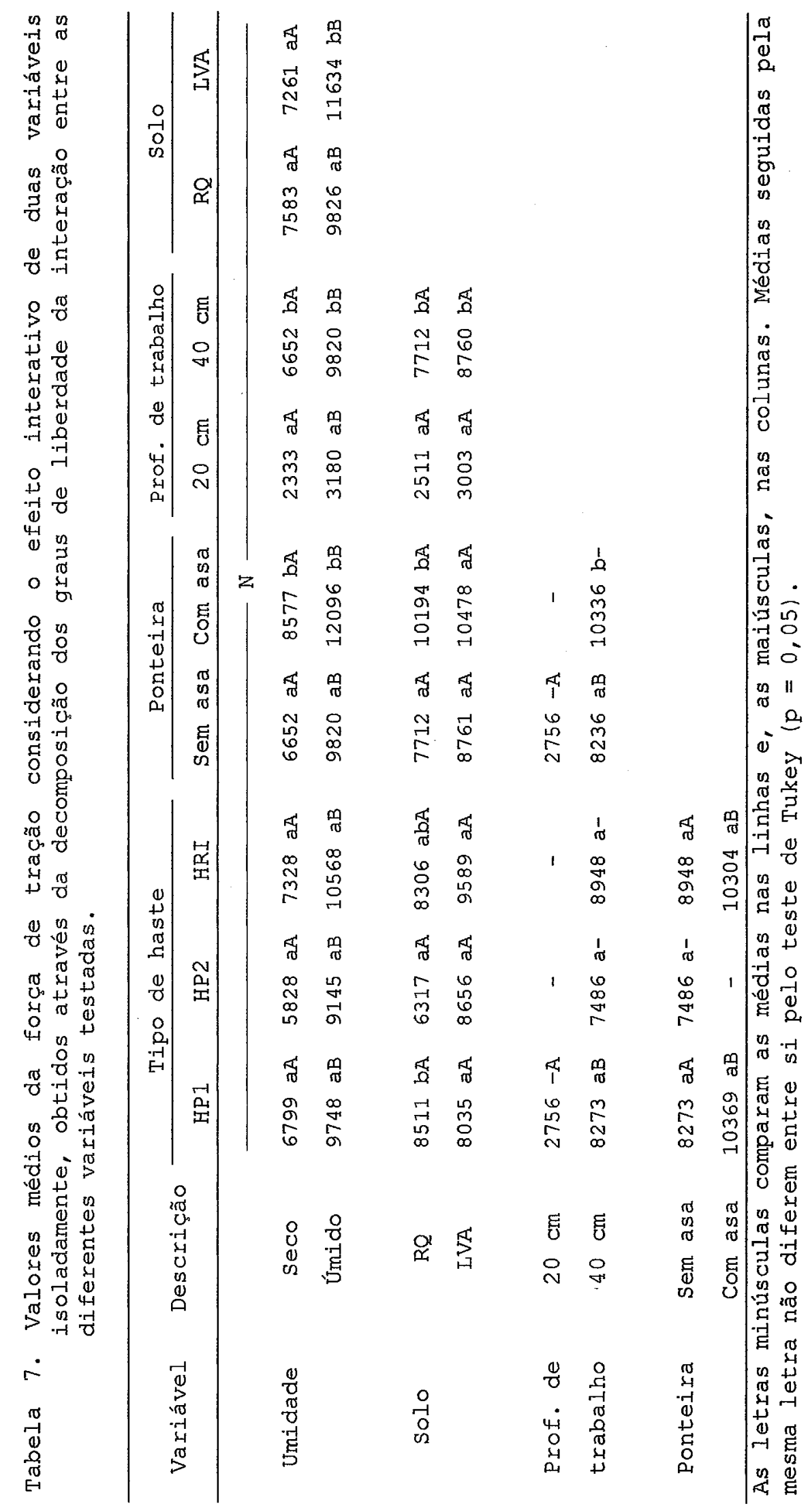




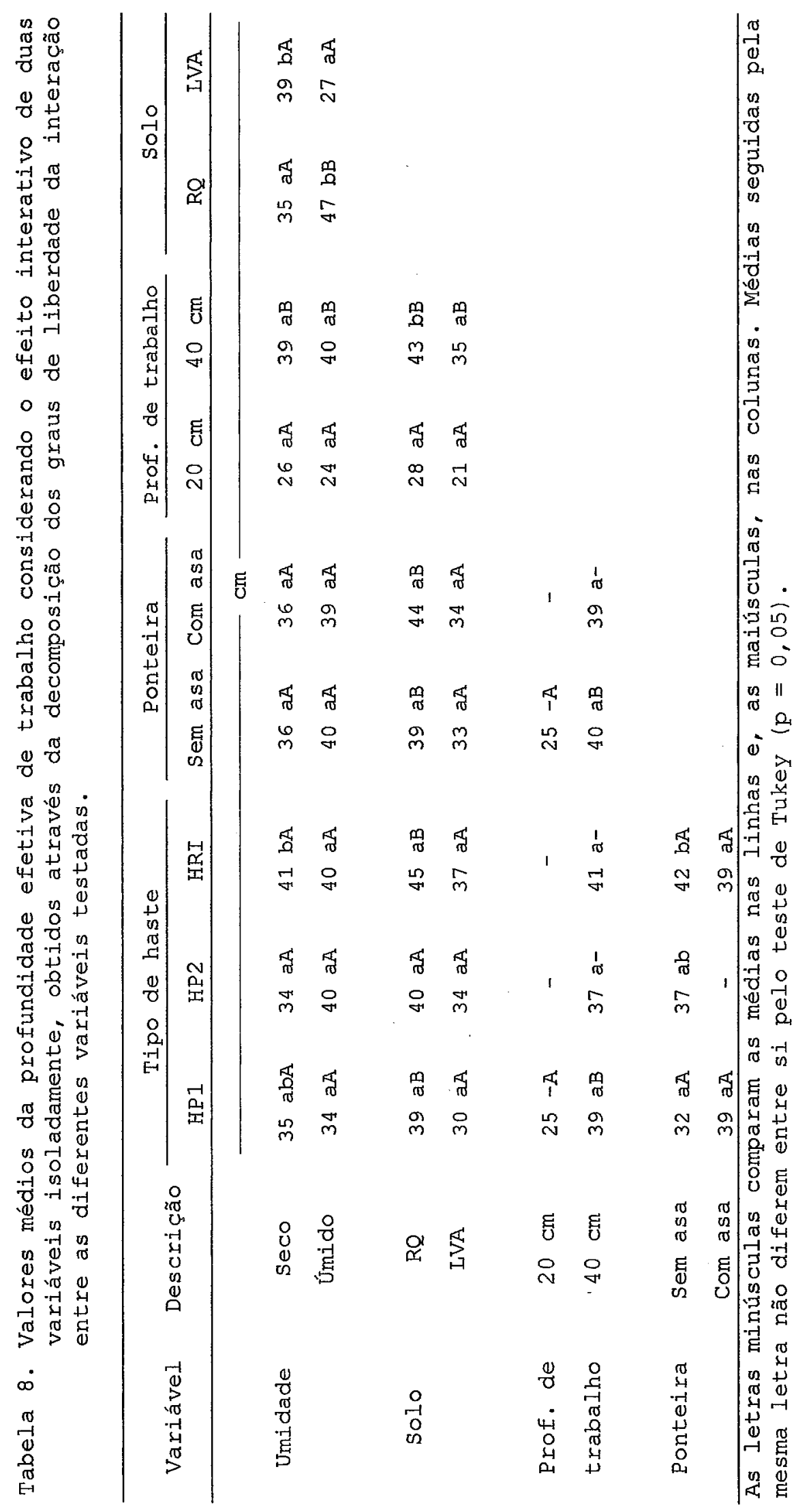


Apesar do menor gasto de energia em sulcos pouco profundos, Bentivenha (2000) observou que sulcos com até $20 \mathrm{~cm}$ de profundidade, tanto no RQ como no IVA, resultaram em menor crescimento do sistema radicular e da parte aérea das mudas de eucalipto até os 11 meses, comparativamente aos sulcos com até $40 \mathrm{~cm}$. Embora esses resultados perdurem por poucos meses em solos porosos, entre 12 a 24 meses pós-plantio, não resultam em expressivo ganho de produtividade de madeira por ocasião da colheita. Apesar disso, o crescimento inicial das plantas pode ser consideravelmente estimulado por maior volume de solo mobilizado, reduzindo a demanda de práticas de controle de plantas invasoras (Gonçalves et al., 2000).

Não houve diferença entre os solos quanto à força de tração e potência na barra de tração exigidas, em função de suas texturas (Tabela 6). Apesar disto, nota-se tendência de maior demanda de força de tração no IVA (Figura 7), devido ao seu maior teor de argila e resistência dinâmica inicial, principalmente quando este encontrava-se seco (U = $3,3 \%$ ) (Figura 4).

Quando os solos estavam secos (Umidade do RQ $\left(U_{\mathrm{RO}}\right)=4,5 \%$; Umidade do IVA $\left(\mathrm{U}_{\mathrm{LVA}}\right)=3,3 \%$ ) houve menor exigência de força de tração e potência na barra de tração para mobilizálos (Tabela 6 e Figura 7). Resultados semelhantes foram observados por santos Filho (1993), ao constatar que, em níveis extremos de umidade no solo (muito. secos ou muito úmidos), maior força é requisitada para tracionar os implementos. 


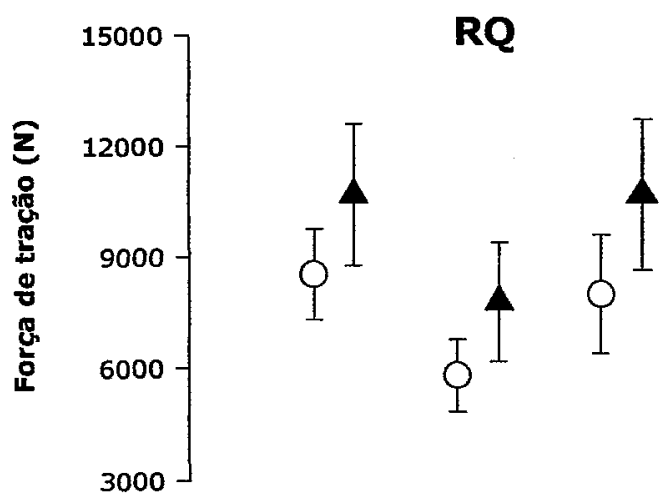

LVA

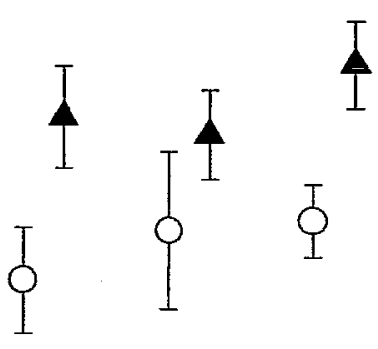

Solo úmido $\left(U_{\mathrm{RQ}}=5,7 \% ; U_{\mathrm{LVA}}=17,4 \%\right)$
Solo seco $\left(U_{\mathrm{RQ}}=4,5 \% ; U_{\mathrm{LVA}}=3,3 \%\right)$
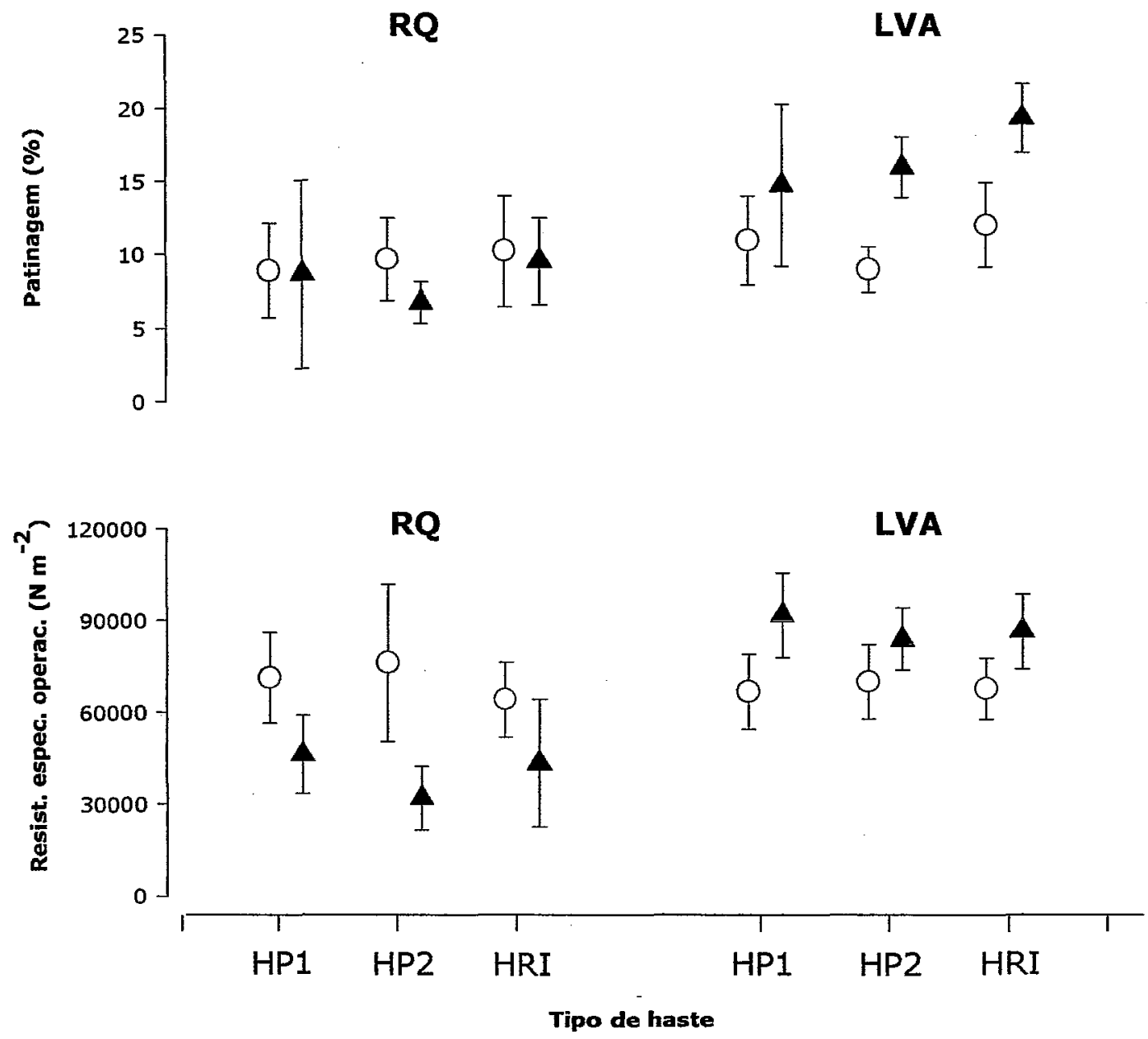

Figura 7. Força de tração, patinagem e resistência específica operacional de acordo com o tipo de haste, solo e umidade. 
A maior profundidade efetiva de trabalho alcançada no RQ, quando este estava úmido (Tabela 8), foi a causa da maior demanda de força de tração para este solo. Quanto ao LVA, a maior demanda de força de tração com o aumento da umidade do solo deve estar relacionada à maior adesão de solo ao implemento. Esta maior adesão justifica-se por um teor de umidade próximo à capacidade de campo (umidade do solo na preparo $=17,4 \frac{\circ}{5}$; umidade na capacidade de campo $=$ 18\%). Segundo Beltrame (1983), a umidade do solo mais apropriada para o uso de subsoladores está situada abaixo do limite inferior de plasticidade.

A velocidade de deslocamento, numa mesma umidade e textura do solo, não diferiu em função do tipo de haste, presença ou não de asas nas ponteiras e profundidade de trabalho (Tabela 6), devido à condução do trator em marcha e rotação do motor constantes $e$, por serem os solos leves e não compactados.

Estudos realizados por Taylor \& Beltrame (1980), mostraram que um trator com tração nas quatro rodas pode tracionar até $60 \%$ de seu peso. Com base nestas informações, o trator utilizado no ensaio (peso aproximado de 6,0 t), possuía capacidade de tração de 35280 N. Considerando que a maior demanda de tração entre os tratamentos testados foi de $13000 \mathrm{~N}$, houve sobra de $22280 \mathrm{~N}$ de capacidade de tração. Caso os solos em estudo tivessem teores de argila e silte mais elevados e/ou camadas adensadas, com demanda de potência maior do que a do trator, a velocidade de deslocamento poderia ser afetada. Por outro lado, a velocidade de deslocamento foi $7 \%$ menor com 0 solo úmido e $7 \%$ 
menor no LVA, efeito talvez atribuído à maior patinagem nestas condições (Figura 7 e Tabela 6).

A presença de asas na ponteira, a profundidade de trabalho, a textura e a umidade do solo afetaram, acentuadamente, a patinagem (Tabelas 6 e 9 e, Figura 7). Em média, a patinagem foi $22 \%$ maior com a presença de asas na ponteira, 39\% maior com o preparo de solo realizado até 40 $\mathrm{cm}$, 37\% maior no LVA e 25\% maior com o solo úmido. No LVA, a patinagem com o solo úmido foi $42 \%$ maior do que com o solo seco; no $R Q$, não foi detectado aumento da patinagem com o solo úmido (Tabela 9). Este efeito é relativo à menor aderência e à maior plasticidade do LVA, características estreitamente relacionadas ao teor e composição mineralógica da fração argila.

Quando as demais variáveis foram constantes, exceto para a presença ou não de asas na ponteira, houve diferenças entre os tipos de hastes, quanto à resistência específica operacional (Tabela 10). Houve maior demanda de força para mobilizar uma mesma quantidade de solo na ausência de asas na ponteira, numa maior profundidade de trabalho, no solo mais argiloso, LVA, e sob condições de maior teor de umidade no solo (Tabelas 6 e 10, Figura 7). Isto indica que a propagação da ação desagregadora das hastes é negativamente correlacionada com estas variáveis. Tendo como exemplo a haste HP1, constatou-se que a resistência específica operacional, em média, foi $45 \%$ maior com o solo úmido, $44 \%$ maior no LVA, $50 \%$ maior à profundidade de $40 \mathrm{~cm}$ e $40 \%$ menor com o uso de asas na ponteira (Tabela 10). 


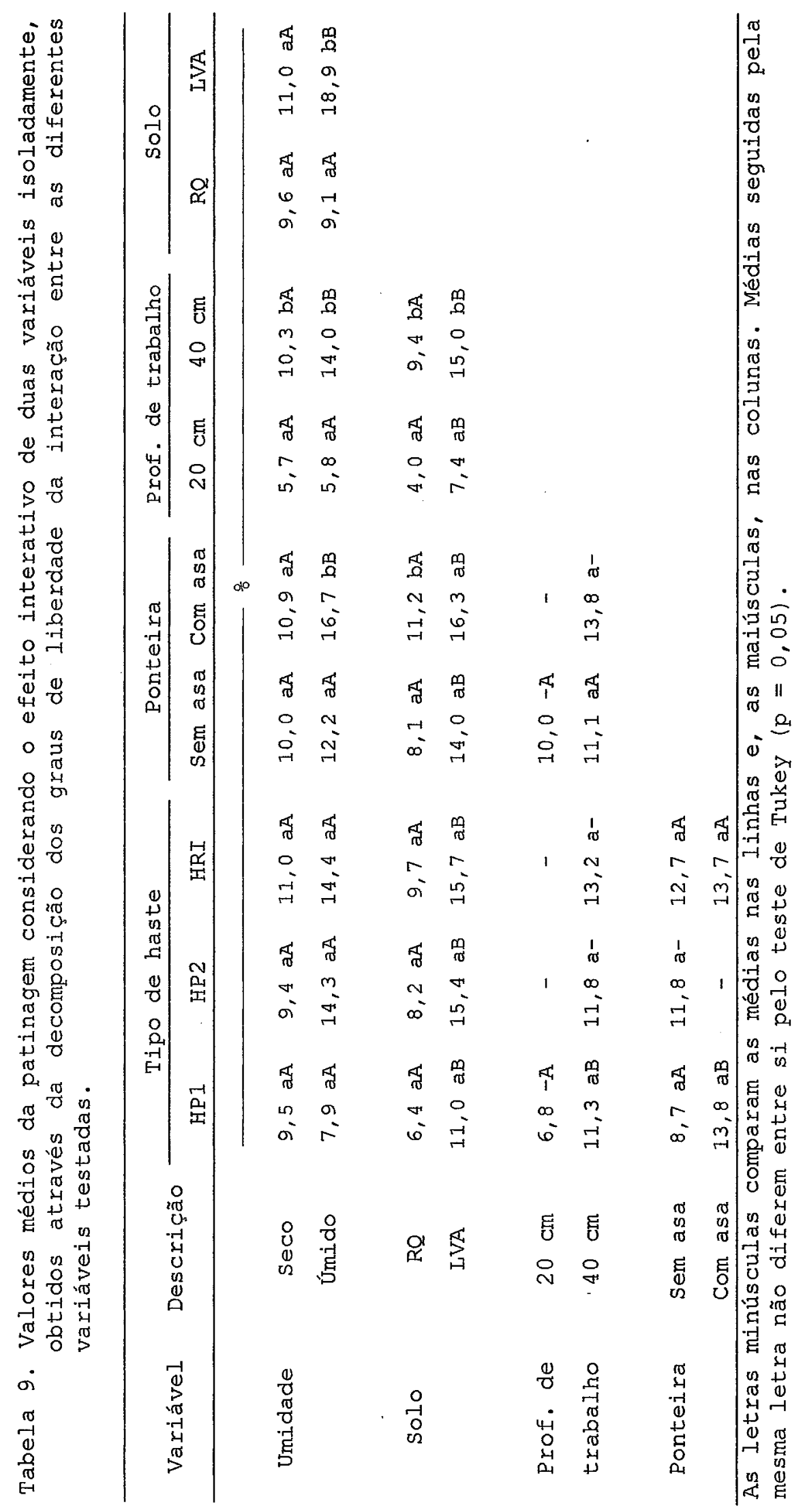




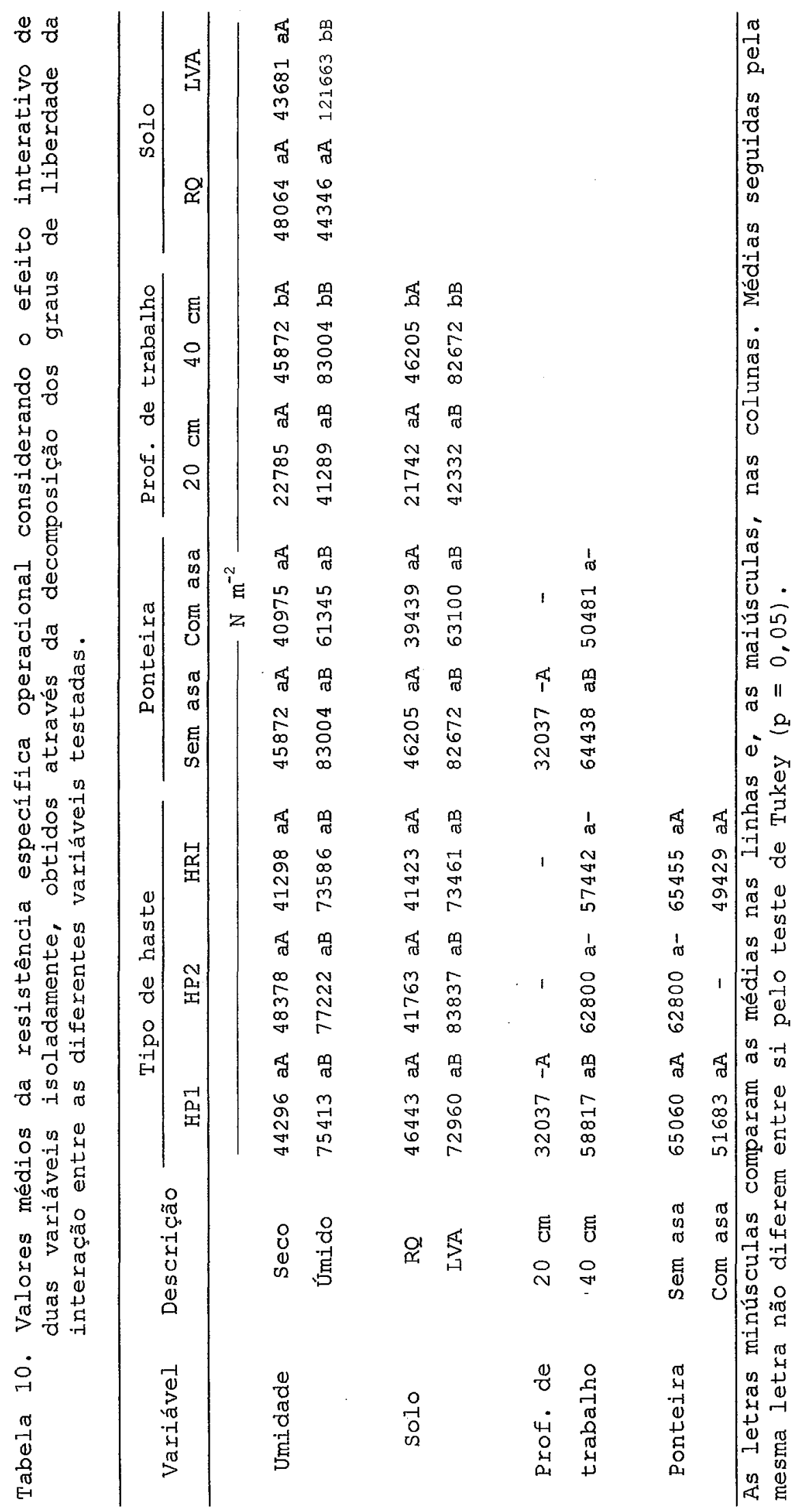


A capacidade efetiva de trabalho não foi influenciada pelo tipo de haste, ponteira e profundidade de trabalho, apenas pelo tipo e umidade do solo (Tabela 6). Em relação ao tipo de solo, a capacidade efetiva de trabalho no RQ foi de 0,93 hectare trabalhado por hora e, no LVA, 0,86. Isso se deve à maior velocidade de deslocamento (7\%) e menor patinagem (37\%) no RQ. Quanto à umidade do solo, sua influência na velocidade de deslocamento e patinagem foi o principal fator que afetou a capacidade efetiva de trabalho.

A profundidade efetiva de trabalho não foi afetada pela ponteira e umidade do solo, somente pelo tipo de haste e textura do solo (Tabelas 6 e 8). Quando muito, a profundidade efetiva de trabalho foi apenas $5 \mathrm{~cm}$ menor do que a planejada. A menor profundidade efetiva de trabalho no LVA está estreitamente relacionada à maior resistência dinâmica deste solo no período seco (Figura 4) e à maior resistência especifica operacional ao ser preparado a até $40 \mathrm{~cm}$ (Tabela 10). Lanças (1988) observou que a profundidade efetiva de trabalho também não foi afetada pela e ponteira.

A área de solo mobilizada foi afetada pelo tipo de haste, presença ou não de asas na ponteira e pelo tipo de solo (Tabela 6). A maior área de solo mobilizada no RQ ocorreu, principalmente, à maior profundidade efetiva de trabalho (Tabela 8) e à maior facilidade de movimentação das partículas deste solo. A ponteira com asa mobilizou cerca de $30 \%$ mais solo que a ponteira sem asa. Resultados semelhantes também foram observados por Fernandes et al. (1981), Gill \& Vanderberg (1968), Iuanças (1987) e Lanças (1988). 


\section{CONCLUSÕES}

1. As três hastes avaliadas, duas parabólicas e uma reta inclinada, não diferiram entre si quanto a demanda por força de tração e desempenho operacional. Houve diferença para a profundidade efetiva de trabalho e a área de solo mobilizado, parâmetros em que a haste retainclinada apresentou os melhores resultados;

2. As ponteiras com asa apresentaram cerca de $20 \%$ a mais de força de tração, $22 \%$ menos resistência especifica operacional e mobilizaram $20 \%$ mais solo do que as ponteiras sem asa;

3. Com o aumento da profundidade de trabalho, de 20 para 40 $\mathrm{cm}$, houve incremento da força de tração, potência na barra de tração e patinagem;

4. Não houve diferença entre os solos quanto à força de tração exigida, apesar do LVA apresentar 37\% a mais de patinagem e $42 \%$ a mais de resistência especifica operacional, quando comparado com $\circ$ RQ. O LVA também apresentou menor profundidade efetiva de trabalho e menor área de solo mobilizado; 
5. Independentemente do tipo de haste, presença ou não de asas na ponteira, profundidade de trabalho e tipo de solo, a demanda de força de tração foi menor para o solo seco. O solo seco proporcionou menor patinagem, menor resistência específica operacional e maior capacidade efetiva de trabalho, quando comparado com o solo úmido. 


\section{REFERÊNCIAS BIBLIOGRÁFICAS}

American Society of Agricultural Engineers - ASAE. Terminology and definitions for soil tillage and soil-tool relationships. Engineering Practice, EP 291.1, p. 229241,1982 .

BALASTREIRE, L. A. Máquinas Agrícolas. São Paulo, Ed. Manole, 1987. $310 \mathrm{p}$.

BELTRAME, I. F. S. Avaliação do desempenho de três subsoladores em latossolo vermelho escuro. Engenharia Agrícola, v.7, n.1, p. 37-52, 1983.

BENTIVENHA, S. R. P. Mobilização de solos, com diferentes texturas e umidade, por hastes subsoladoras e crescimento inicial de povoamentos de Eucalyptus grandis. Piracicaba, 2000. ? p. Dissertação (Mestrado) - Escola Superior de Agricultura "Luiz de Queiroz", Universidade de São Paulo.

BICUDO, S. J. Subsolador: algumas relações entre profundidade de trabalho, largura das sapatas e número de hastes. Botucatu, 1990. 130 p. Tese (Doutorado) Faculdade de Ciências Agronômicas, Universidade Estadual Paulista.

CASSEL, D.K. Subsoiling crop and soils magazine. v.32, n.1, out. 1979 .

CASTRO, O. M. Preparo do solo para culturas anuais. In: Manual Técnico de Manejo e Conservação de Solo e Água tecnologias para aumentar a cobertura vegetal e a 
infiltração de água no solo. Campinas, 1994. Manual CATI, n. 40 , p. $61-87$.

DRANSFIELD, P.; WILLATT, S.T.; WILLIS, A.H. Soil to implement reaction experenced with simple tines at various angles of attack. Journal of Agricultural Engineering Research, V.9, n.3, p. 220-234, 1965.

EMPRESA BRASILEIRA DE PESQUISA AGROPECUARIA. Manual de métodos de análise de solo. Rio de Janeiro, 1997. $212 \mathrm{p}$.

EMPRESA BRASILEIRA DE PESQUISA AGROPECUÁRIA. Sistema Brasileiro de Classificação de Solos. Brasilia, 1999. 412 p.

FERNANDES, J.; FURLANI NETO, V. L. \& STOLF, R. Dimensionamento do subsolador alado. Brasil Açucareiro. v.97, n.2, p. 32-38, 1981.

FERNANDES, J. Mobilização do solo para cana-de-açúcar. Piracicaba, 1985. 117 p.

FERRETTI, G. Avaliação do desempenho operacional de um arado de aivecas em um Latossolo Roxo. Campinas: FEAGRI, 1992. Dissertação (Mestrado) - Unicamp.

GADANHA JÚNIOR, C. D.; MOLIN, J. P.; COELHO, J. L. D.; YAHN, C. H.; TOMIMORI, S. M. A. Máquinas e implementos agrícolas do Brasil. São Paulo: SCT/CNPq/IBICT/IPT/CIENTEC/NSI-MA, 1991. $468 \mathrm{p}$. 
GARNER, T.H.; REYNOLDS, W.R.; MUSEN, H.L.; MILES, G.E.; DAVIS, J.W.; WOLE, D.; PEIPER, U.M. Energy requirement for subsoiling Coastal Plain Soils. Transactions of the ASAE, v. 30, n.2, p. 343-349, 1987.

GILL, W. R. \& VANDERBERG, G. E. Soil dynamics in tillage and traction. Washington: Agricultural Research Service, United States Department of Agriculture, 1968. 511 p.

GONÇALVES, J.L.M.; STAPE, J.L.; BENEDETTI, V.; EESSEL, V.A.G. \& GAVA, J.I. Reflexos do cultivo mínimo e intensivo do solo em sua fertilidade e nutrição das árvores. In: GONÇALVES, J.L.M. \& BENEDETTI, V. (eds.) Nutrição e Fertilização Florestal. Piracicaba: IPEF, 2000. cap. 1, p. $1-57$.

LANÇAS, K.P. Subsolador: desempenho em função de formas geométricas de hastes, tipos de ponteiras e número de hastes. Botucatu, 1987. 112 p. Dissertação (Mestrado) Faculdade de Ciências Agronômicas, Universidade Estadual Paulista.

LANÇAS, K.P. Subsolador: desempenho em função de formas geométricas de hastes, tipos de ponteiras e número de hastes. Botucatu, 1988. 171 p. Tese (Doutorado) Faculdade de Ciências Agronômicas, Universidade Estadual Paulista.

LANÇAS, K.P.; BENEZ, S.H. Avaliação dos resultados operacionais obtidos para três formas geométricas de hastes subsoladoras. Energia na Agricultura, v.4, n.1, p. 27-34, 1989. 
MIALHE, L. G. Máquinas agrícolas: ensaios \& certificação. Piracicaba: Fundação de Estudos Agrários Luiz de Queiroz (FEALQ), 1996. 722 p.

NICHOLS, M.I.; REAVES, C.A. Soil reaction to subsoiling equipment. Agricultural Engineering, v.39, n.6, p. 340343,1958 .

O'CALLAGHAN, J.R.; MCCULLEN, P.J. Clevage of soil by inclined and wedge shaped tines. Journal of Agricultural Engineering Research, v.10, n.3, p. 248-254, 1965.

OWEN, G.T. Soil disturbance associated with deep subsoiling in compact soils. Canadian Agricultural Enginnering, v.30, n.1, p. 33-37, 1987.

PAYNE, P.C.J. The relationship between mechanical properties of soil and performance of simple cultivation implements. Journal of Agricultural Engineering Research, v.1, n.1, p. $23-50,1956$.

PAYNE, P.C.J.; TANNER, D.W. The relationship between rake angle and the performance of simple cultivation implements. Journal of Agricultural Engineering Research, v.4, n.4, p. $312-325,1959$.

RÍPOLI, T. C.; MIALHE, L. G.; NAKAMURA, R. T. Subsolagem e subsoladores. Piracicaba: Centro Acadêmico Luiz de Queiroz - Departamento Editorial, 1985. 34 p. 
SANTOS FILHO, A. G. Desempenho energético e operacional em função da velocidade de deslocamento e teor de água no solo. Botucatu, 1993. 141 p. Dissertação (Mestrado) Faculdade de Ciências Agronômicas, Universidade Estadual Paulista.

SEIXAS, F. Compactação do solo devido à mecanização florestal - causas, efeitos e práticas de controle. Circular Técnica IPEF, n.163, 10 p., 1988.

SEIXAS, F. Avaliação de impactos da colheita de madeira no solo. Piracicaba: ESATQ/USP, 1996. 21p.

SEIXAS, F. Avaliação da compactação de solos e sua influência na produtividade e qualidade da floresta. In: SIMPÓSIO BRASILEIRO SOBRE COLHEITA E TRANSPORTE FLORESTAL, 4., Campinas, 1999. Anais. Campinas: SIF, 1999. p.14-35.

SIEMENS, J.C.; WEBER, J.A.; THORNBURN, J.H. Mechanics of soil as influenced by model tillage tools. Transactions of the ASAE, V.8, n.1, p. 1-7, 1965.

SILVA, J. R.; MESQUITA, C. M.; KURACHI. S. A. H.; TESTA, A. Avaliação de peças ativas de subsoladores quanto à exigência de tração. Boletim Técnico IAC, n. 94, 15 p, $1984 \mathrm{a}$.

SILVA, J. R.; KURACHI. S. A. H.; MESQUITA, C. M.; BARRETO, J. N.; PETRONI, A. C. Correlação entre esforço de tração e profundidade de subsolagem. Boletim Técnico IAC, n. 96, 16 p, $1984 b$. 
SOUZA, W.R. Subsolador: influência de parâmetros geométricos na distribuição das forças. Campinas, 1989. 114 p. Dissertação (Mestrado) - Unicamp.

SPOOR, G. ; GODWIN, R.J. An experimental investigation into the deep loosening of soil by rigid tines. Journal of Agricultural Engineering Research, v.23, p. 243-258, 1978.

SRIVASTAVA, A. K.; GOERING, C. E.; ROHRBACH, R. P. Engineering principles of agricultural machines. Michigan: American Society of Agricultural Engineers - ASAE, 1993. $602 \mathrm{p}$.

STAFFORD, J.V. The perfomance of a rigid tine in relation to soil properties and speed. Journal of Agricultural Engineering Research, v.24, n.1, p. 41-55, 1979.

STOLF, R. ; FERNANDES, J. ; FURLANI NETO, V. Penetrômetro de impacto modelo IAA/PLANALSUCAR: recomendações para seu uso. Araras: Instituto do Açúcar e do Álcool, 1982. 19 p.

TAYLOR, J. C. ; BELTRAME. L. F. S. Por que, quando e como utilizar a subsolagem. Lavoura Arrozeira. Porto Alegre, p. 34-44, mai/jun 1980 .

TELISCHI, B.; MCCOLLY, H.F.; ERICKSON, E. Draft measurement for tillage tools. Agricultural Engineering, v.37, n.9, p. 605-608, 1956. 